\title{
Measurements of Local Heat Flux and Water-Side Heat Transfer Coefficient in Water Wall Tubes
}

\author{
Jan Taler and Dawid Taler
}

Additional information is available at the end of the chapter

http://dx.doi.org/10.5772/52959

\section{Introduction}

Measurements of heat flux and heat transfer coefficient are subject of many current studies. A proper understanding of combustion and heat transfer in furnaces and heat exchange on the water-steam side in water walls requires accurate measurement of heat flux which is absorbed by membrane furnace walls. There are three broad categories of heat flux measurements of the boiler water-walls: (1) portable heat flux meters inserted in inspection ports [1], (2) Gardon type heat flux meters welded to the sections of the boiler tubes [1-4], (3) tubular type instruments placed between two adjacent boiler tubes [5-14]. Tubular type and Gardon meters strategically placed on the furnace tube wall can be a valuable boiler diagnostic device for monitoring of slag deposition. If a heat flux instrument is to measure the absorbed heat flux correctly, it must resemble the boiler tube as closely as possible so far as radiant heat exchange with the flame and surrounding surfaces is concerned. Two main factors in this respect are the emissivity and the temperature of the absorbing surface, but since the instrument will almost always be coated with ash, it is generally the properties of the ash and not the instrument that dominate the situation. Unfortunately, the thermal conductivity can vary widely. Therefore, accurate measurements will only be performed if the deposit on the meter is representative of that on the surrounding tubes. The tubular type instruments known also as flux-tubes meet this requirement. In these devices the measured boiler tube wall temperatures are used for the evaluation of the heat flux $q_{m}$. The measuring tube is fitted with two thermocouples in holes of known radial spacing $r_{1}$ and $r_{2}$. The thermocouples are led away to the junction box where they are connected differentially to give a flux related electromotive force.

The use of the one dimensional heat conduction equation for determining temperature distribution in the tube wall leads to the simple formula 


$$
q_{m}=\frac{k\left(f_{1}-f_{2}\right)}{r_{o} \ln \left(r_{1} / r_{2}\right)} .
$$

The accuracy of this equation is very low because of the circumferential heat conduction in the tube wall.

However, the measurement of the heat flux absorbed by water-walls with satisfactory accuracy is a challenging task. Considerable work has been done in recent years in this field. Previous attempts to accurately measure the local heat flux to membrane water walls in steam boilers failed due to calculation of inside heat transfer coefficients. The heat flux can only be determined accurately if the inside heat transfer coefficient is measured experimentally.

New numerical methods for determining the heat flux in boiler furnaces, based on experimentally acquired interior flux-tube temperatures, will be presented. The tubular type instruments have been designed to provide a very accurate measurement of absorbed heat flux $q_{m}$, inside heat transfer coefficient $h_{i n}$, and water steam temperature $T_{f}$.

Two different tubular type instruments (flux tubes) were developed to identify boundary conditions in water wall tubes of steam boilers.

The first meter is constructed from a short length of eccentric bare tube containing four thermocouples on the fire side below the inner and outer surfaces of the tube. The fifth thermocouple is located at the rear of the tube on the casing side of the water wall tube. First, formulas for the view factor defining the heat flux distribution at the outer surface of the flux tube were derived. The exact analytical expressions for the view factor compare very well with approximate methods for determining view factor which are used by the ANSYS software. The meter is constructed from a short length of eccentric tube containing four thermocouples on the fireside below the inner and outer surfaces of the tube. The fifth thermocouple is located at the rear of the tube (on the casing side of the water-wall tube). The boundary conditions on the outer and inner surfaces of the water flux-tube must then be determined from temperature measurements at the interior locations. Four K-type sheathed thermocouples, $1 \mathrm{~mm}$ in diameter, are inserted into holes, which are parallel to the tube axis. The thermal conduction effect at the hot junction is minimized because the thermocouples pass through isothermal holes. The thermocouples are brought to the rear of the tube in the slot machined in the tube wall. An austenitic cover plate with the thickness of $3 \mathrm{~mm}$ - welded to the tube - is used to protect the thermocouples from the incident flame radiation. A K-type sheathed thermocouple with a pad is used to measure the temperature at the rear of the flux-tube. This temperature is almost the same as the water-steam temperature.

The non-linear least squares problem was solved numerically using the LevenbergMarquardt method. The temperature distribution at the cross section of the flux tube was determined at every iteration step using the method of separation of variables.The heat transfer conditions in adjacent boiler tubes have no impact on the temperature distribution in the flux tubes. 
The second flux tube has two longitudinal fins which are welded to the eccentric bare tube. In contrast to existing devices, in the developed flux-tube fins are not welded to adjacent water-wall tubes. Temperature distribution in the flux-tube is symmetric and not disturbed by different temperature fields in neighboring tubes. The temperature dependent thermal conductivity of the flux-tube material was assumed. An inverse problem of heat conduction was solved using the least squares method. Three unknown parameters were estimated using the Levenberg-Marquardt method. At every iteration step, the temperature distribution over the cross-section of the heat flux meter was computed using the ANSYS CFX software. Test calculations were carried out to assess accuracy of the presented method. The uncertainty in determined parameters was calculated using the variance propagation rule by Gauss. The presented method is appropriate for membrane water-walls.

The developed meters have one particular advantage over the existing flux tubes to date.The temperature distribution in the flux tube is not affected by the water wall tubes, since the flux tube is not connected to adjacent waterwall tubes with metal bars, referred to as membrane or webs. To determine the unknown parameters only the temperature distribution at the cross section of the flux tube must be analysed.

\section{Tubular type heat flux meter made of a bare tube}

Heat flux meters are used for monitoring local waterwall slagging in coal and biomass fired steam boilers [5-19].

The tubular type instruments (flux tubes) [10-14,19] and other measuring devices [15-18] were developed to identify boundary conditions in water wall tubes of steam boilers. The meter is constructed from a short length of eccentric tube containing four thermocouples on the fire side below the inner and outer surfaces of the tube. The fifth thermocouple is located at the rear of the tube on the casing side of the water wall tube.

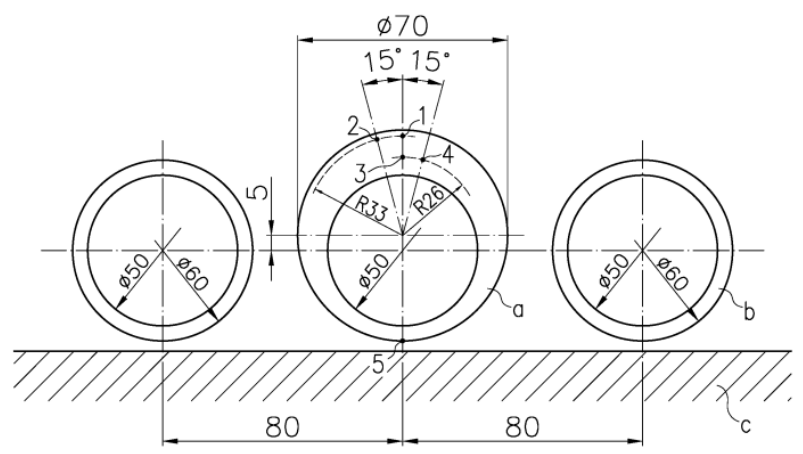

Figure 1. The heat flux tube placed between two water wall tubes, $a-$ flux tube, $b-$ water wall tube, $c-$ thermal insulation

The boundary conditions at the outer and inner surfaces of the water flux-tube must then be determined from temperature measurements at the interior locations. Four K-type sheathed 
thermocouples, $1 \mathrm{~mm}$ in diameter, are inserted into holes, which are parallel to the tube axis. The thermal conduction effect at the hot junction is minimized because the thermocouples pass through isothermal holes. The thermocouples are brought to the rear of the tube in the slot machined in the protecting pad. An austenitic cover plate with the thickness of $3 \mathrm{~mm}$ welded to the tube is used to protect the thermocouples from the incident flame radiation. A K-type sheathed thermocouple with a pad is used to measure the temperature at the rear of the flux-tube. This temperature is almost the same as the water-steam temperature. A method for determining fireside heat flux, heat transfer coefficient on the inner surface and temperature of water-steam mixture in water-wall tubes is developed. The unknown parameters are estimated based on the temperature measurements at a few internal locations from the solution of the inverse heat conduction problem. The non-linear least squares problem is solved numerically using the Levenberg-Marquardt method. The diameter of the measuring tube can be larger than the water-wall tube diameter. The view factor defining the distribution of the heat flux on the measuring tube circumference is determined using exact analytical formulas and compared with the results obtained numerically using ANSYS software. The method developed can also be used for an assessment of scale deposition on the inner surfaces of the water wall tubes or slagging on the fire side. The presented method is suitable for water walls made of bare tubes as well as for membrane water walls. The heat transfer conditions in adjacent boiler tubes have no impact on the temperature distribution in the flux tubes.

\subsection{View factor for radiation heat transfer between heat flux tube and flame}

The heat flux distribution in the flux tube depends heavily on the heat flux distribution on its outer surface. To determine the heat flux distribution $q$ as a function of angular coordinate $\phi$, the analytical formulas for the view factor $\psi$, defining radiation interchange between an infinitesimal surface on the outer flux tube circumference and the infinite flame or boiler surface, will be derived. The heat flux absorbed by the outer surface of the heat flux tube $q(\varphi)$ is given by

$$
q(\varphi)=q_{m} \psi(\varphi)
$$

The specific thermal load of the water wall $q_{m}$ is defined as the ratio of the heat transfer rate absorbed by the water wall to the projected surface area of the water wall. The view factor is the fraction of the radiation leaving the surface element located on the flux tube surface that arrives at the flame surface. The view factor can be computed from

$$
\psi=\frac{1}{2}\left(\sin \delta_{1}+\sin \delta_{2}\right)
$$

The angles $\delta$ and $\delta_{2}$ are formed by the normal to the flux tube at $\varphi$ and the tangents to the flux tube and adjacent water-wall tube (Figures 2,4,6). Positive values of $\delta_{1}$ are measured clockwise with respect to the normal while positive values of $\delta_{2}$ are measured counterclockwise with respect to the normal. The radial coordinate $r_{o}$ of the flux tube outer surface measured from the center 0 (Figure 2) is 


$$
r_{o}=e \cos \varphi+\sqrt{b^{2}-e^{2}(\sin \varphi)^{2}} .
$$

where: $e$ - eccentric (Figure 2), $b$ - outer radius of flux-tube.

The angle $\varphi_{1}$ can be expressed in terms of the angle $\varphi$, flux tube outer radius $b$, and eccentric $e$ (Figure 2)

$$
\begin{gathered}
\varphi_{1}=\arcsin \left[\frac{\left(e \cos \varphi+\sqrt{b^{2}-(e \sin \varphi)^{2}}\right) \sin \varphi}{b}\right], \quad \varphi_{1} \leq \frac{\pi}{2}, \\
\varphi_{1}=\pi-\arcsin \left[\frac{\left(e \cos \varphi+\sqrt{b^{2}-(e \sin \varphi)^{2}}\right) \sin \varphi}{b}\right], \quad \frac{\pi}{2} \leq \varphi_{1} \leq \pi .
\end{gathered}
$$

First, the view factor for the angle interval $0 \leq \varphi_{1} \leq \varphi_{1, l 1}$ was determined

$$
\psi=\frac{1+\cos \varphi_{1}}{2}, 0 \leq \varphi_{1} \leq \varphi_{1, l 1}
$$

The limit angle $\varphi_{1, l 1}$ (Figures 2 and 3 ) is given by

$$
\varphi_{1, l 1}=\arccos \frac{c-e}{b}
$$

where $c$ is the outer radius of the boiler tube.

Next the view factor in the angle interval $\varphi_{1, l 1} \leq \varphi_{1} \leq \varphi_{1, l 2}$ will be determined. The limit angle $\varphi_{1, l 2}$ is: $\varphi_{1, l 2}=\varphi_{1}(\varphi=\pi / 2)=(\pi / 2)+\arcsin (e / b)$ (Figure3). The view factor $\psi$ is computed from Eq.(2), taking into account that (Figure 4)

$$
\begin{gathered}
\delta_{1}=\frac{\pi}{2}, \quad \delta_{2}=\frac{\pi}{2}-\left(\varepsilon+\varphi_{1}\right), \varepsilon=\beta+\gamma-\frac{\pi}{2}, x_{i}=b \sin \varphi_{1}, x_{i}=b \cos \varphi_{1}, \\
\beta=\arcsin \frac{c}{\sqrt{\left(t-x_{i}\right)^{2}+\left(y_{i}+e\right)^{2}}}, \gamma=\arcsin \frac{t-x_{i}}{\sqrt{\left(t-x_{i}\right)^{2}+\left(y_{i}+e\right)^{2}}}, \varphi_{l 1} \leq \varphi_{1} \leq \varphi_{l 2^{\prime}}
\end{gathered}
$$

where $t$ is the pitch of the water wall tubes.

Next the view factor $\psi(\phi)$ is determined in the angle interval $\varphi_{1, l 2} \leq \varphi_{1} \leq \varphi_{1, l 3}$ (Figures 3 and 5). 


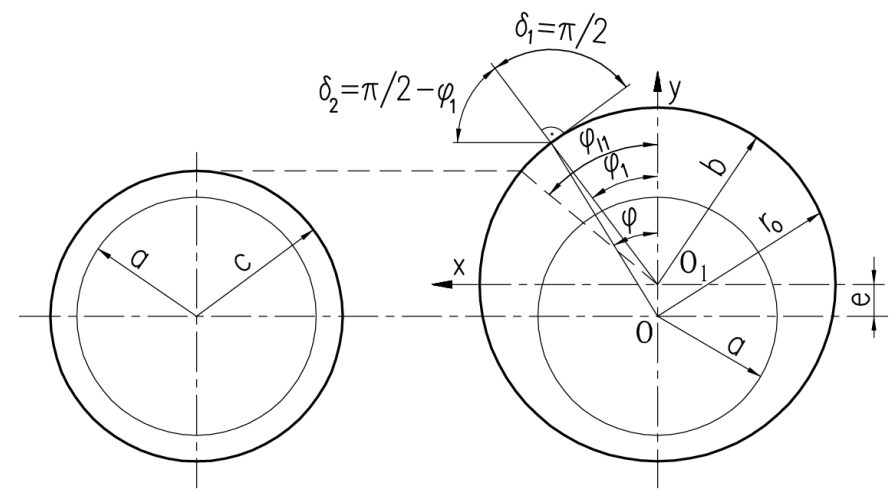

Figure 2. Determination of view factor in the angle interval $0 \leq \varphi_{1} \leq \varphi_{1, l 1}$

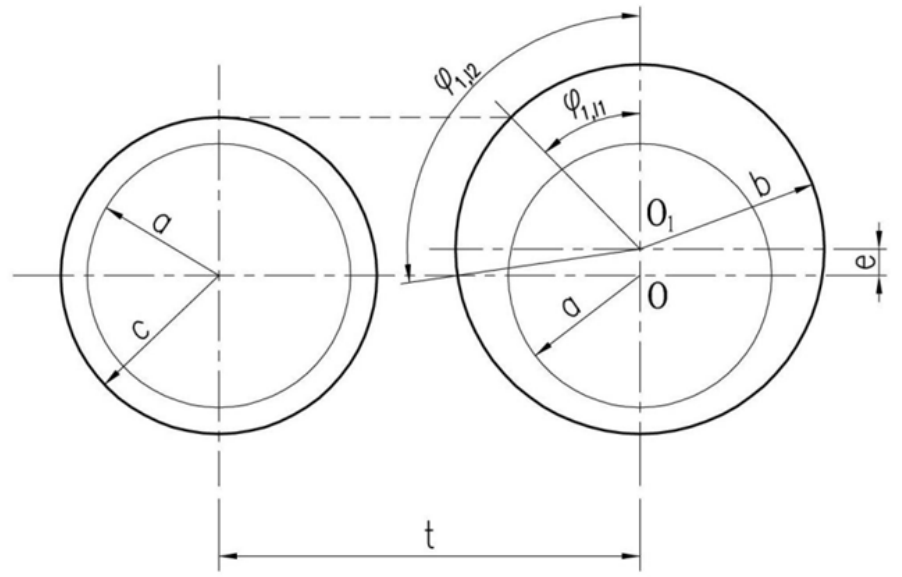

Figure 3. Limit angles $\varphi_{1, l 1}$ and $\varphi_{1, l 2}$

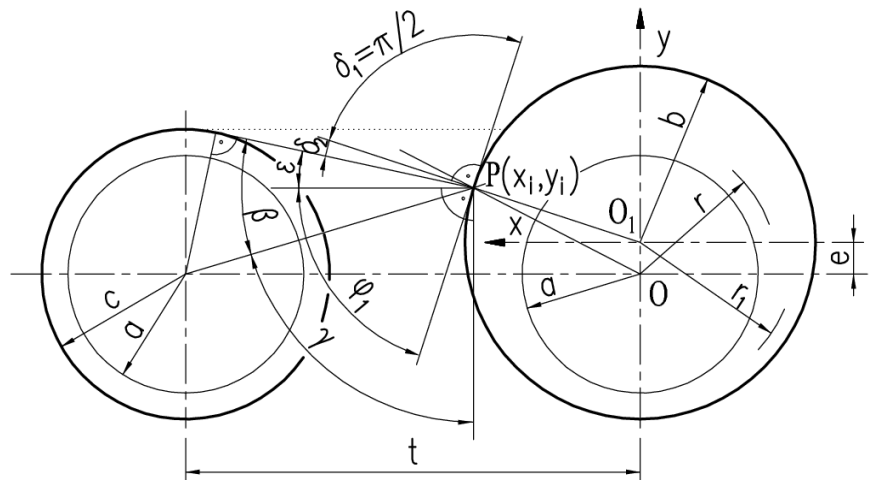

Figure 4. Determination of view factor in the angle interval $\varphi_{1, l 1} \leq \varphi_{1} \leq \varphi_{1, l 2}$ 


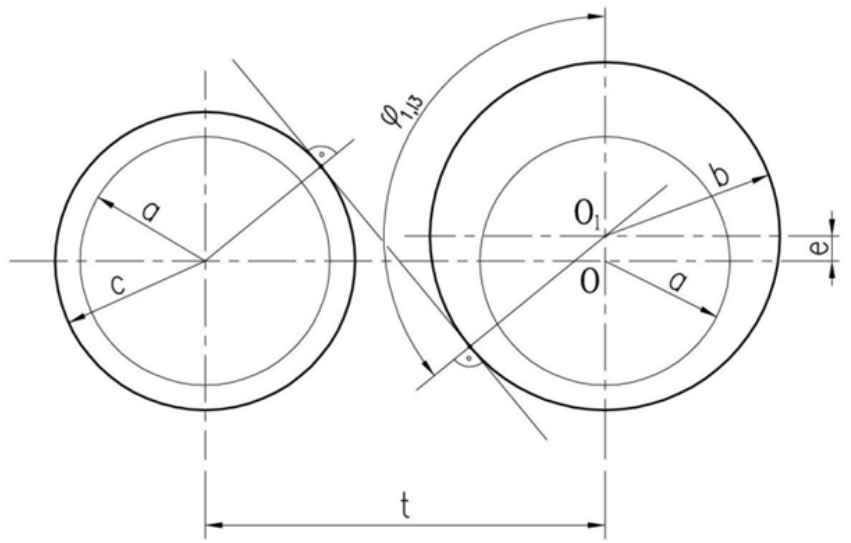

Figure 5. Limit angle $\varphi_{1, l 3}$

The limit angle $\varphi_{1,13}$ (Figure 5) can be expressed as

$$
\varphi_{1,13}=\frac{\pi}{2}+\omega+\kappa
$$

where the angles $\kappa$ i $\omega$ are given by

$$
\begin{gathered}
\kappa=\arctan \frac{b-c}{t}, \\
\omega=\arccos \frac{b+c}{\sqrt{t^{2}+e^{2}}} .
\end{gathered}
$$

The view factor $\psi$ in the interval $\varphi_{1, l 2} \leq \varphi_{1} \leq \varphi_{1, l 3}$ is calculated from the following expression (Figure 6)

$$
\psi=\frac{1}{2}\left(\sin \delta_{2}-\sin \delta_{1}\right), \varphi_{1, l 2} \leq \varphi_{1} \leq \varphi_{1, l 3}
$$

where

$$
\begin{gathered}
\delta_{1}=\frac{\pi}{2} \\
\delta_{2}=\varepsilon+\varphi_{1}-\frac{\pi}{2} \\
\varepsilon=\beta+\gamma-\frac{\pi}{2}
\end{gathered}
$$




$$
\begin{gathered}
\beta=\arcsin \frac{c}{\sqrt{\left(t-x_{i}\right)^{2}+\left(y_{i}+e\right)^{2}}}, \\
\gamma=\pi-\arcsin \frac{t-x_{i}}{\sqrt{\left(t-x_{i}\right)^{2}+\left(y_{i}+e\right)^{2}}}, \\
x_{i}=b \sin \varphi_{1} \\
y_{i}=b \cos \varphi_{1} .
\end{gathered}
$$

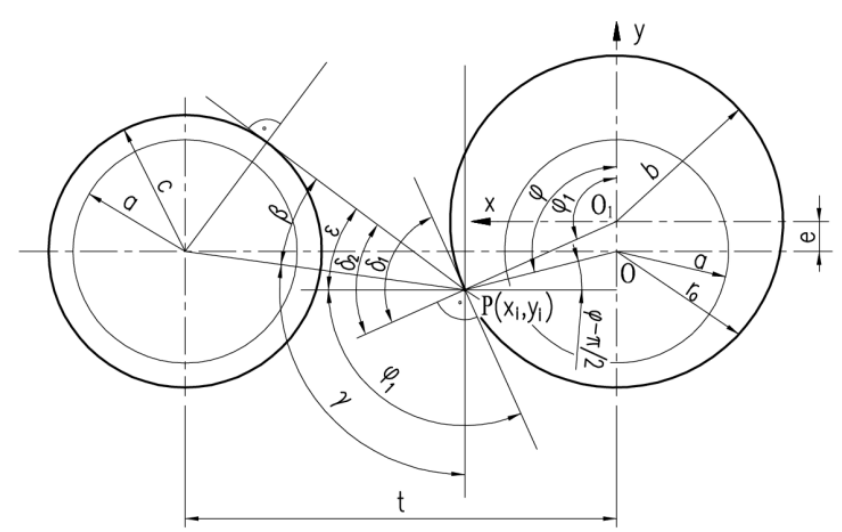

Figure 6. Determination of view factor in the angle interval $\varphi_{1, l 2} \leq \varphi_{1} \leq \varphi_{1, l 3}$

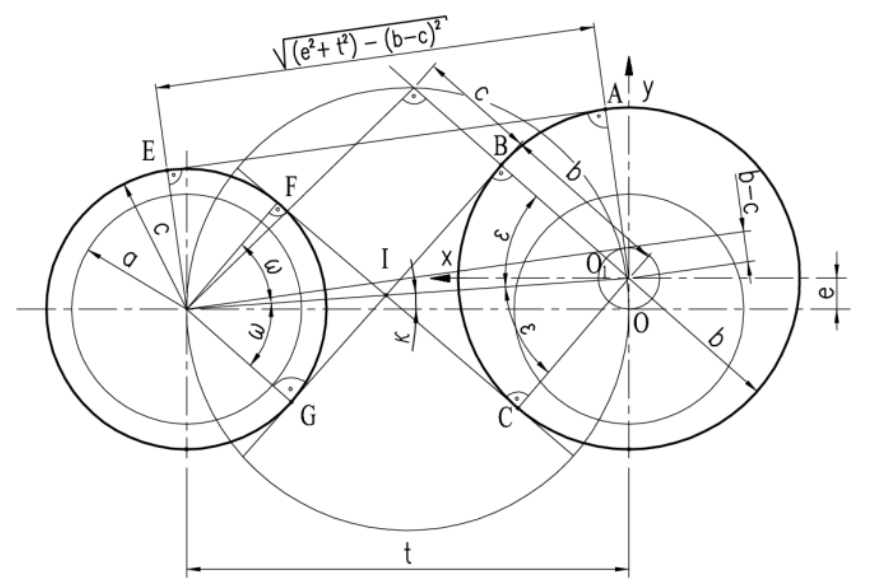

Figure 7. Determination of mean view factor $\psi_{b s}$ for boiler setting over tube pitch $t$ using the crossed string method 
Radiation leaving the flame reaches also the boiler setting. The view factor for the radiation heat exchange between boiler setting and rear side of the measuring tube can be calculated in similar way as for the forward part. The mean heat flux $q_{b s}$ resulting from the radiation heat transfer between the flame and the boiler setting can be determined using the crossedstring method [20-21].

The mean value of the view factor $\psi_{b s}$ over the pitch length $t$ is calculated from (Figure7)

$$
\psi_{b s}=\frac{1}{2 t}[(F C+B G)-(F G+B C)]
$$

After substituting the lengths of straight FC and BG and circular segments FG and BC into Eq. (21), the mean value of the view factor over the boiler setting can be expressed as:

$$
\psi_{b s}=\frac{b+c}{t}(\tan \omega-\omega)
$$

The mean heat flux over the setting surface is

$$
q_{b s}=q_{m} \psi_{b s}
$$

The angle $\omega$ is determined from

$$
\tan \omega=\frac{\sqrt{e^{2}+t^{2}-(b+c)^{2}}}{b+c}
$$

If the diameters of the heat flux and water wall tubes are equal, then Eq.(24) simplifies to

$$
\tan \omega=\sqrt{\left(\frac{t}{2 c}\right)^{2}-1}
$$

The view factor for the radiation heat exchange between boiler setting and rear side of the measuring tube can be calculated in similar way as for the forward part. The view factor in the angle interval $\varphi_{1, l 4} \leq \varphi_{1} \leq \varphi_{1, l 5}$ (Figure 8), accounting for the setting radiation, is given by

$$
\psi=\psi_{b s} \cdot \frac{1}{2}\left(\sin \delta_{2}-\sin \delta_{1}\right), \varphi_{1, l 4} \leq \varphi_{1} \leq \varphi_{1, l 5}
$$

where the limit angle $\varphi_{1, l 4}$ is (Figure 8)

$$
\psi_{1,14}=\frac{\pi}{2}-\omega+\kappa
$$




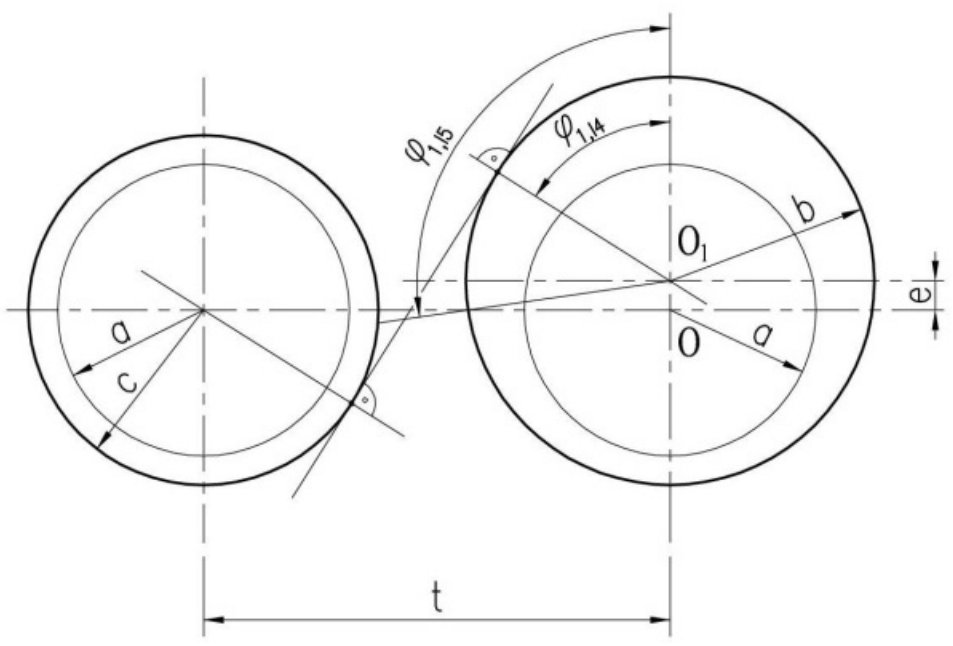

Figure 8. Limit angles $\varphi_{1, l 4}$ and $\varphi_{1,15}=\varphi_{1, l 2}=(\pi / 2)+\arcsin (e / b)$

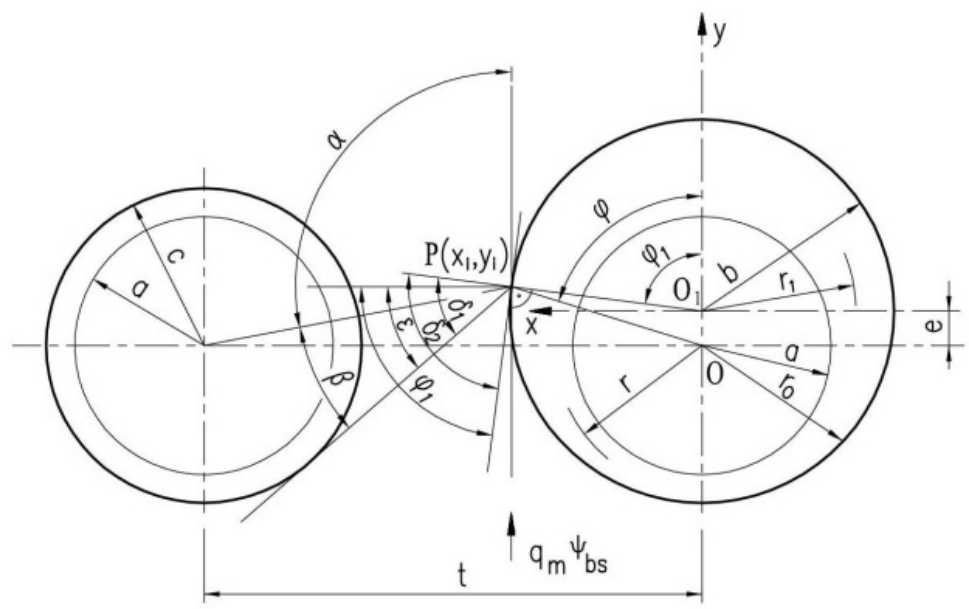

Figure 9. Determination of view factor in the angle interval $\varphi_{1, l 4} \leq \varphi_{1} \leq \varphi_{1,15}$

The angles $\delta_{1}$ and $\delta_{2}$ are (Figure 9)

$$
\begin{gathered}
\delta_{1}=\frac{\pi}{2}+\varepsilon-\varphi_{1}, \\
\delta_{2}=\frac{\pi}{2},
\end{gathered}
$$


where

$$
\begin{gathered}
\varepsilon=\beta+\gamma-\frac{\pi}{2}, \\
\beta=\arcsin \frac{c}{\sqrt{\left(t-x_{i}\right)^{2}+\left(y_{i}+e\right)^{2}}}, \\
\gamma=\pi-\arcsin \frac{t-x_{i}}{\sqrt{\left(t-x_{i}\right)^{2}+\left(y_{i}+e\right)^{2}}}, \\
x_{i}=b \sin \varphi_{1}, \\
y_{i}=b \cos \varphi_{1} .
\end{gathered}
$$

The view factor $\psi$ in the interval $\varphi_{1, l 5} \leq \varphi \leq \pi$, where $\varphi_{1, l 5}=\varphi_{1, l 2}$, is given by

$$
\psi=\psi_{b s} \cdot \frac{1}{2}\left(\sin \delta_{1}+\sin \delta_{2}\right), \varphi_{1, l 5} \leq \varphi \leq \pi
$$

where

$$
\begin{gathered}
\delta_{1}=\varphi_{1}-\varepsilon-\frac{\pi}{2}, \\
\delta_{2}=\frac{\pi}{2}, \\
\varepsilon=\frac{\pi}{2}-(\gamma-\beta), \\
\gamma=\arcsin \frac{c}{\sqrt{\left(t-x_{i}\right)^{2}+\left(y_{i}+e\right)^{2}}} \\
\pi-\arcsin \frac{t-x_{i}}{\sqrt{\left(t-x_{i}\right)^{2}+\left(y_{i}+e\right)^{2}}}, \\
x_{i}=b \cos \left(\varphi_{1}-\frac{\pi}{2}\right), \\
y_{i}=-b \sin \left(\varphi_{1}-\frac{\pi}{2}\right) .
\end{gathered}
$$




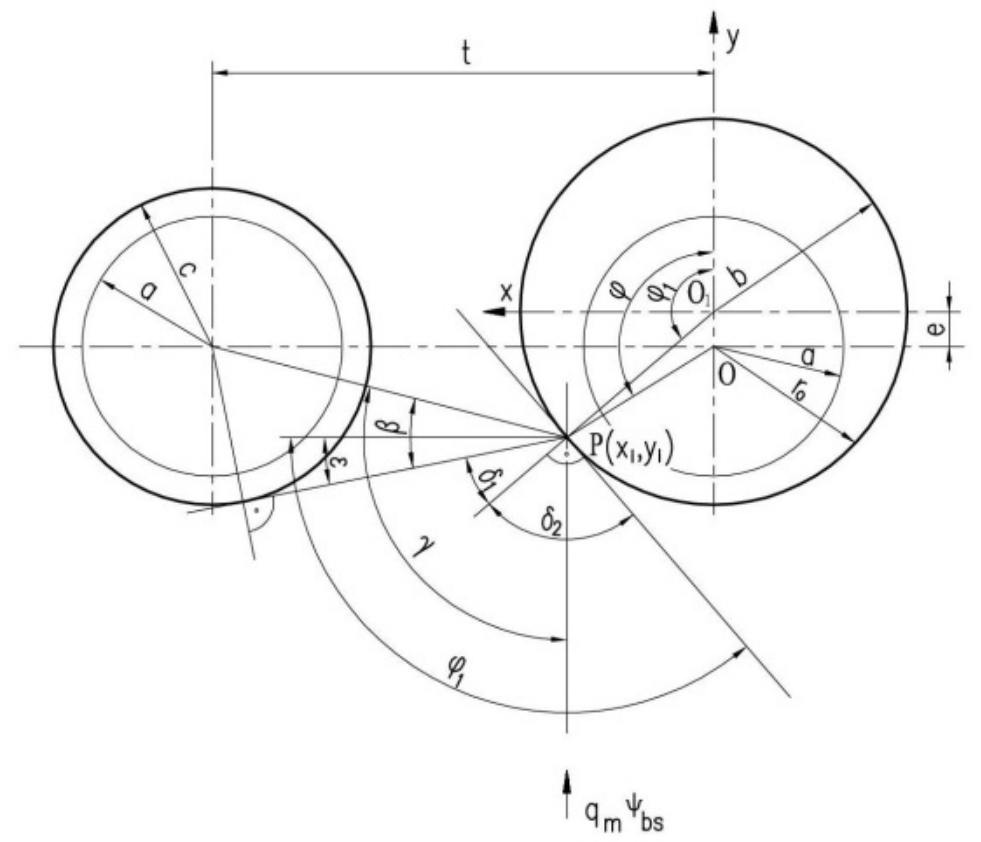

Figure 10. Determination of view factor in the angle interval $\varphi_{1,15} \leq \varphi_{1} \leq \pi$

The total view factor accounts for the radiation heat exchange between the heat flux tube and flame and between the heat flux tube and the boiler setting.

\subsection{Theory of the inverse problem}

At first, the temperature distribution at the cross section of the measuring tube will be determined, i.e. the direct problem will be solved. Linear direct heat conduction problem can be solved using an analytical method. The temperature distribution will also be calculated numerically using the finite element method (FEM). In order to show accuracy of a numerical approach, the results obtained from numerical and analytical methods will be compared. The following assumptions have been made:

- thermal conductivity of the flux tube material is constant,

- heat transfer coefficient at the inner surface of the measuring tube does not vary on the tube circumference,

- rear side of the water wall, including the measuring tube, is thermally insulated,

- diameter of the eccentric flux tube is larger than the diameter of the water wall tubes,

- the outside surface of the measuring flux tube is irradiated by the flame, so the heat absorption on the tube fire side is non-uniform.

The cylindrical coordinate system is shown in Figure11. 


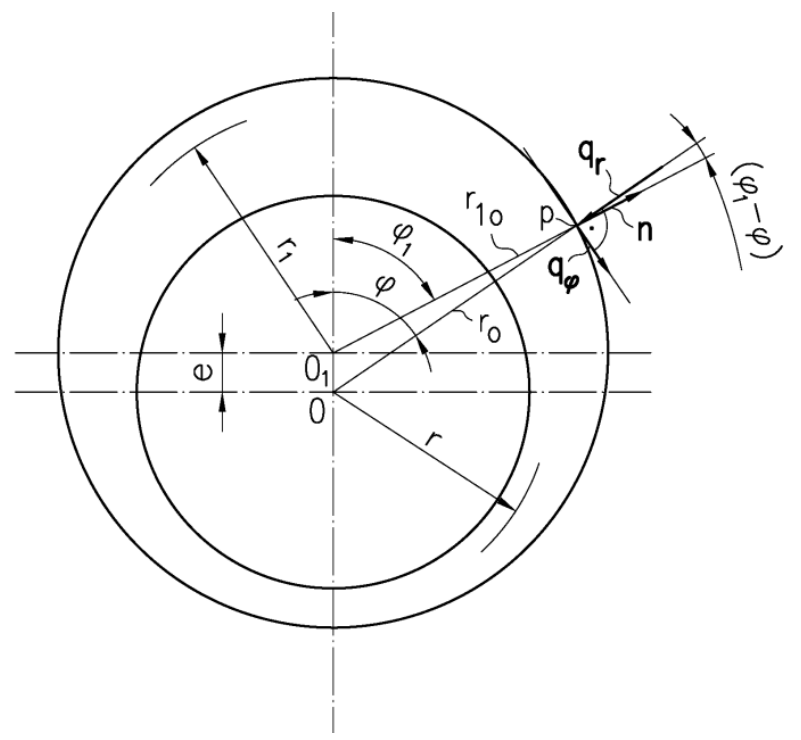

Figure 11. Approximation of the boundary condition on the outer tube surface

The temperature distribution in the eccentric heat flux tube is governed by heat conduction

$$
\frac{1}{r} \frac{\partial}{\partial r}\left(k r \frac{\partial \theta}{\partial r}\right)+\frac{1}{r} \frac{\partial}{\partial \varphi}\left(\frac{k}{r} \frac{\partial \theta}{\partial \varphi}\right)=0
$$

subject to the following boundary conditions

$$
\begin{gathered}
\left.k \nabla \theta \cdot \mathbf{n}\right|_{r=r_{o}}=q_{m} \psi(\varphi) \\
\left.k \frac{\partial \theta}{\partial r}\right|_{r=a}=\left.h \theta\right|_{r=a}
\end{gathered}
$$

The left side of Eq. (44) can be transformed as follows (Figure11)

$$
\begin{aligned}
& \left.k \nabla \theta \cdot \mathbf{n}\right|_{r=r_{o}}=\left.\left(\mathbf{q}_{\mathrm{r}}+\mathbf{q}_{\varphi}\right) \cdot \mathbf{n}\right|_{r=r_{o}}= \\
& =\left.\left[k \frac{\partial T}{\partial r} \cos \left(\varphi_{1}-\varphi\right)+\frac{k}{r} \frac{\partial T}{\partial \varphi} \sin \left(\varphi_{1}-\varphi\right)\right]\right|_{r=r_{o}}
\end{aligned}
$$

The second term in Eq. (46) can be neglected since it is very small and the boundary condition (44) simplifies to

$$
\left.k \frac{\partial \theta}{\partial r}\right|_{r=r_{o}}=\frac{q_{m} \psi(\varphi)}{\cos \left(\varphi_{1}-\varphi\right)}
$$


The heat flux over the tube circumference can be approximated by the Fourier polynomial

$$
\frac{q_{m} \psi(\varphi)}{\cos \left(\varphi_{1}-\varphi\right)}=q_{0}+\sum_{n=1}^{\infty} q_{n} \cos (n \varphi)
$$

where

$$
\begin{aligned}
& q_{0}=\frac{1}{\pi} \int_{0}^{\pi} \frac{q_{m} \psi(\varphi)}{\cos \left(\varphi_{1}-\varphi\right)} d \varphi, \\
& q_{n}=\frac{2}{\pi} \int_{0}^{\pi} \frac{q_{m} \psi(\varphi)}{\cos \left(\varphi_{1}-\varphi\right)} \cos (n \varphi) d \varphi, n=1, \ldots
\end{aligned}
$$

The boundary value problem $(43,45,47)$ was solved using the separation of variables to give

$$
\theta(r, \varphi)=A_{0}+B_{0} \ln r+\sum_{n=1}^{\infty}\left(C_{n} r^{n}+D_{n} r^{-n}\right) \cos n \varphi .
$$

where

$$
\begin{gathered}
A_{0}=\frac{q_{0} r_{o}(\varphi)}{k}\left(\frac{1}{B i}-\ln a\right), \\
B_{0}=\frac{q_{0} r_{o}(\varphi)}{k}, \\
C_{n}=\frac{q_{n} r_{o}(\varphi)}{k} \frac{\frac{1}{n} u^{n}(B i+n) \frac{1}{a^{n}}}{B i\left(u^{2 n}+1\right)+n\left(u^{2 n}-1\right)}, \\
D_{n}=-\frac{q_{n} r_{o}(\varphi)}{k} \frac{\frac{1}{n} u^{n}(B i-n) a^{n}}{B i\left(u^{2 n}+1\right)+n\left(u^{2 n}-1\right)} .
\end{gathered}
$$

The ratio of the outer to inner radius of the eccentric flux tube: $u=u(\phi)=r_{o}(\phi) / a$ depends on the angle $\phi$, since the outer radius of the tube flux

$$
r_{o}=e \cos \varphi+\sqrt{b^{2}-(e \sin \varphi)^{2}}
$$

is the function of the angle $\phi$.

Eq. (50) can be used for the temperature calculation when all the boundary conditions are known. In the inverse heat conduction problem three parameters are to be determined:

- absorbed heat flux referred to the projected furnace wall surface: $x_{1}=q_{m}$,

- heat transfer coefficient on the inner surface of the boiler tube: $x_{2}=h$,

- fluid bulk temperature: $x_{3}=T_{f}$. 
These parameters appear in boundary conditions (44) and (45) and will be determined based on the wall temperature measurements at $m$ internal points $\left(r_{i}, \phi_{i}\right)$

$$
T\left(r_{i}, \varphi_{i}\right)=f_{i}, i=1, \ldots, m, m \geq 3 \text {. }
$$

In a general case, the unknown parameters: $x_{1}, \ldots, x_{n}$ are determined by minimizing sum of squares

$$
S=\left(\mathbf{f}-\mathbf{T}_{\mathbf{m}}\right)^{T}\left(\mathbf{f}-\mathbf{T}_{\mathbf{m}}\right),
$$

where $\mathbf{f}=\left(f_{1}, \ldots, f_{m}\right)^{T}$ is the vector of measured temperatures, and $\mathbf{T}_{\mathbf{m}}=\left(T_{1}, \ldots, T_{m}\right)^{T}$ the vector of computed temperatures $T_{i}=T\left(r_{i}, \varphi_{i}\right), i=1, \ldots, m$.

The parameters $x_{1} \ldots x_{n}$, for which the sum (34) is minimum are determined using the Levenberg-Marquardt method [23,25]. The parameters, $\mathbf{x}$, are calculated by the following iteration

$$
\mathbf{x}^{(k+1)}=\mathbf{x}^{(k)}+\boldsymbol{\delta}^{(k)}, k=0,1, \ldots
$$

where

$$
\begin{aligned}
& \boldsymbol{\delta}^{(k)}=\left[\left(\mathbf{J}_{m}^{(k)}\right)^{T} \mathbf{J}_{m}^{(k)}+\mu^{(k)} \mathbf{I}_{n}\right]^{-1} \times \\
& \times\left(\mathbf{J}_{m}^{(k)}\right)^{T}\left[\mathbf{f}-\mathbf{T}_{m}\left(\mathbf{x}^{(k)}\right)\right] .
\end{aligned}
$$

where $\mu^{(k)}$ is the multiplier and $\mathbf{I}_{\mathbf{n}}$ is the identity matrix. The Levenberg-Marquardt method is a combination of the Gauss-Newton method $\left(\mu^{(k)} \rightarrow 0\right)$ and the steepest-descent method $\left(\mu^{(k)} \rightarrow \infty\right)$. The $m \times n$ Jacobian matrix of $T\left(\mathbf{x}^{(k)}, \mathbf{r}_{i}\right)$ is given by

$$
\mathbf{J}^{(k)}=\left.\frac{\partial \mathbf{T}(\mathbf{x})}{\partial \mathbf{x}_{T}}\right|_{\mathbf{x}=\mathbf{x}^{(k)}}=\left[\left.\begin{array}{ccc}
\frac{\partial T_{1}}{\partial x_{1}} & \cdots & \frac{\partial T_{1}}{\partial x_{n}} \\
\cdots & \cdots & \cdots \\
\cdots & \cdots & \cdots \\
\cdots & \cdots & \cdots \\
\frac{\partial T_{m}}{\partial x_{1}} & \cdots & \frac{\partial T_{m}}{\partial x_{n}}
\end{array}\right|_{\mathbf{x}=\mathbf{x}^{(k)}}, \quad m=5, \quad n=3,\right.
$$


The symbol $\mathbf{I}_{n}$ denotes the identity matrix of $n \times n$ dimension, and $\mu^{(\mathrm{k})}$ the weight coefficient, which changes in accordance with the algorithm suggested by Levenberg and Marquardt. The upper index $T$ denotes the transposed matrix. Temperature distribution $T\left(r, \varphi, \mathbf{x}^{(k)}\right)$ is computed at each iteration step using Eq. (50). After a few iterations we obtain a convergent solution.

\subsection{The uncertainty of the results}

The uncertainties of the determined parameters $\mathbf{x}^{*}$ will be estimated using the error propagation rule of Gauss [23-26]. The propagation of uncertainty in the independent variables: measured wall temperatures $f_{j}, j=1, \ldots m$, thermal conductivity $k$, radial and angular positions of temperature sensors $r_{j}, \varphi_{j}, j=1, \ldots m$ is estimated from the following equation

$$
\begin{aligned}
2 \sigma_{x_{i}}= & {\left[\sum_{j=1}^{m}\left(\frac{\partial x_{i}}{\partial f_{j}} \sigma_{f_{j}}\right)^{2}+\left(\frac{\partial x_{i}}{\partial k} \sigma_{k}\right)^{2}+\sum_{j=1}^{m}\left(\frac{\partial x_{i}}{\partial r_{j}} \sigma_{r_{j}}\right)^{2}+\sum_{j=1}^{m}\left(\frac{\partial x_{i}}{\partial \varphi_{j}} \sigma_{\varphi_{j}}\right)^{2}\right]^{1 / 2}, } \\
& i=1,2,3
\end{aligned}
$$

The $95 \%$ uncertainty in the estimated parameters can be expressed in the form

$$
x_{i}=x_{i}^{*} \pm 2 \sigma_{x_{i}}
$$

where $x_{i}^{*}, i=1,2,3$ represent the value of the parameters obtained using the least squares method. The sensitivity coefficients $\partial x_{i} / \partial f_{j}, \partial x_{i} / \partial k, \partial x_{i} / \partial r_{j}$, and $\partial x_{i} / \partial \varphi_{j}$ in the expression (61) were calculated by means of the numerical approximation using central difference quotients:

$$
\frac{\partial x_{i}}{\partial f_{j}}=\frac{x_{i}\left(f_{1}, f_{2}, \ldots, f_{j}+\delta, \ldots, f_{m}\right)-x_{i}\left(f_{1}, f_{2}, \ldots, f_{j}-\delta, \ldots, f_{m}\right)}{2 \delta},
$$

where $\delta$ is a small number.

\subsection{Computational and boiler tests}

Firstly, a computational example will be presented. "Experimental data" are generated artificially using the analytical solution (50).

Consider a water-wall tube with the following parameters (Figure1.):

- $\quad$ outer radius $b=35 \mathrm{~mm}$,

- inner radius $a=25 \mathrm{~mm}$,

- $\quad$ pitch of the water-wall tubes $t=80 \mathrm{~mm}$,

- thermal conductivity $k=28.5 \mathrm{~W} /(\mathrm{m} \cdot \mathrm{K})$, 


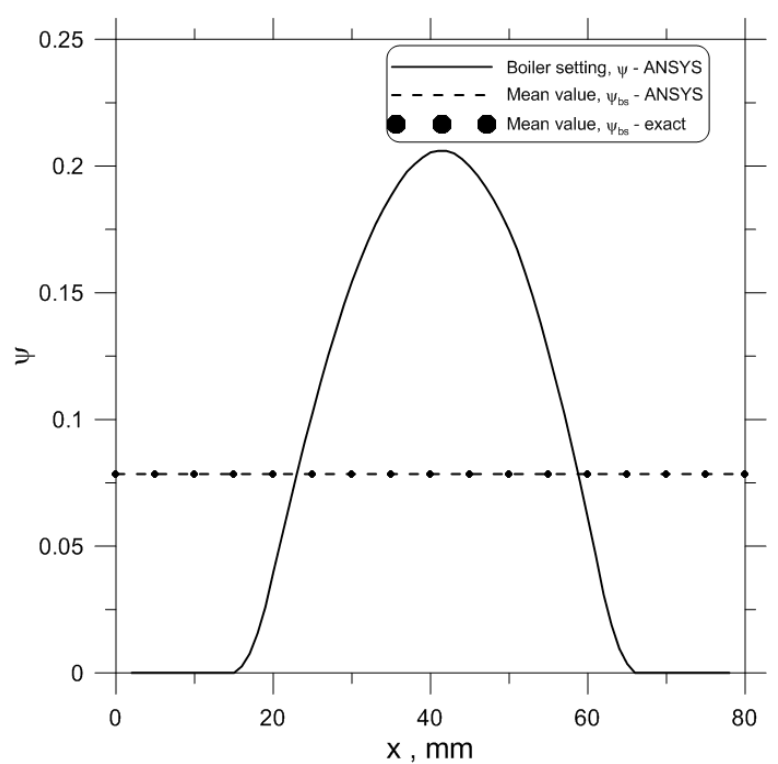

(a)

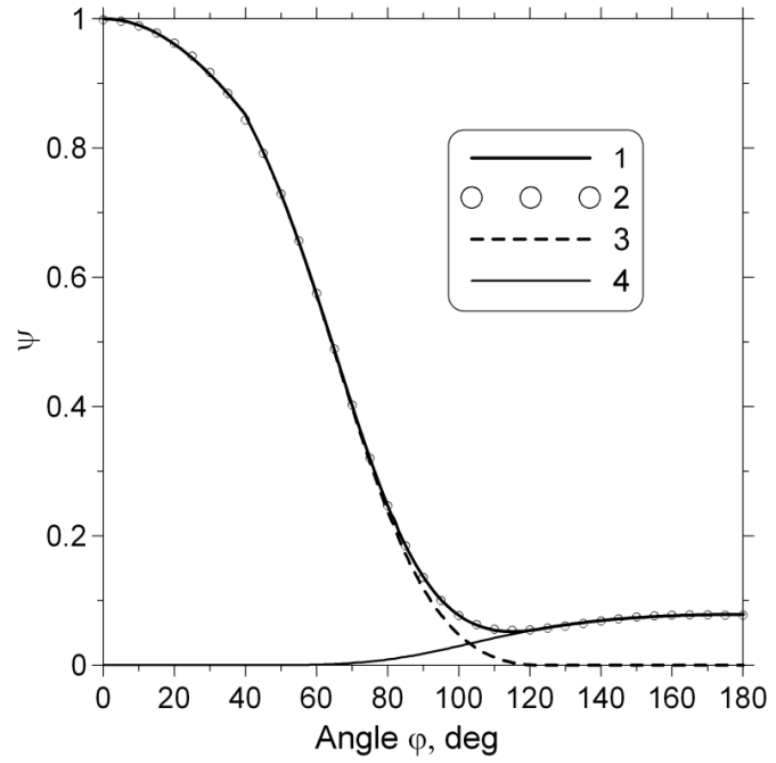

(b)

Figure 12. View factor associated with radiation heat exchange between elemental surface on the boiler setting or flux tube and flame: (a) - view factor for radiation heat transfer between flame and boiler setting, (b) 1 - total view factor accounting radiation from furnace and boiler setting, 2 - approximation by the Fourier polynomial of the seventh degree, 3 - exact view factor for furnace radiation, 4- view factor from boiler setting 
- $\quad$ absorbed heat flux $q_{m}=200000 \mathrm{~W} / \mathrm{m}^{2}$,

- heat transfer coefficient $h=30000 \mathrm{~W} /\left(\mathrm{m}^{2} \cdot \mathrm{K}\right)$,

- $\quad$ fluid temperature $T_{f}=318^{\circ} \mathrm{C}$.

The view factor distributions on the outer surface of the flux-tube and boiler setting were calculated analytically and numerically by means of the finite element method (FEM) [22]. The changes of the view factor over the pitch length and tube circumference are illustrated in Figures 12 and 13.

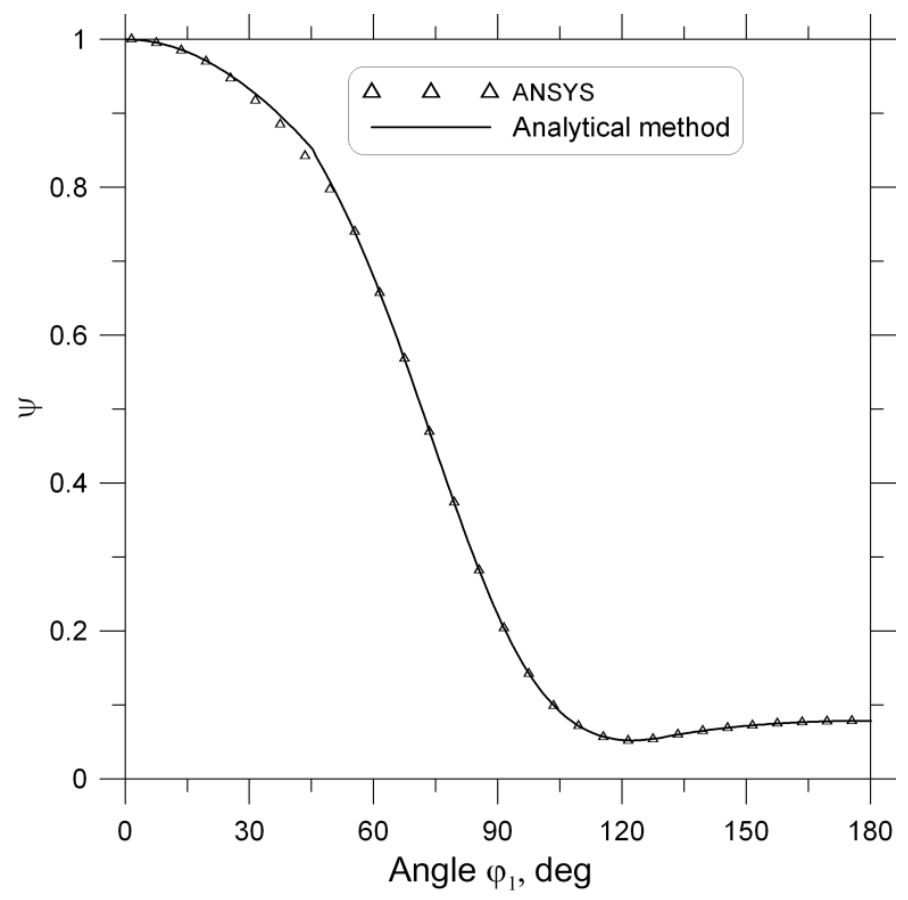

Figure 13. Comparison of total view factor calculated by exact and FEM method

The agreement between the temperatures of the outer and inner tube surfaces which were calculated analytically and numerically is also very good (Figures 14 and 15). The small differences between the analytical and FEM solutions are caused by the approximate boundary condition (47). The temperature distribution in the flux tube cross section is shown in Figure 14. 


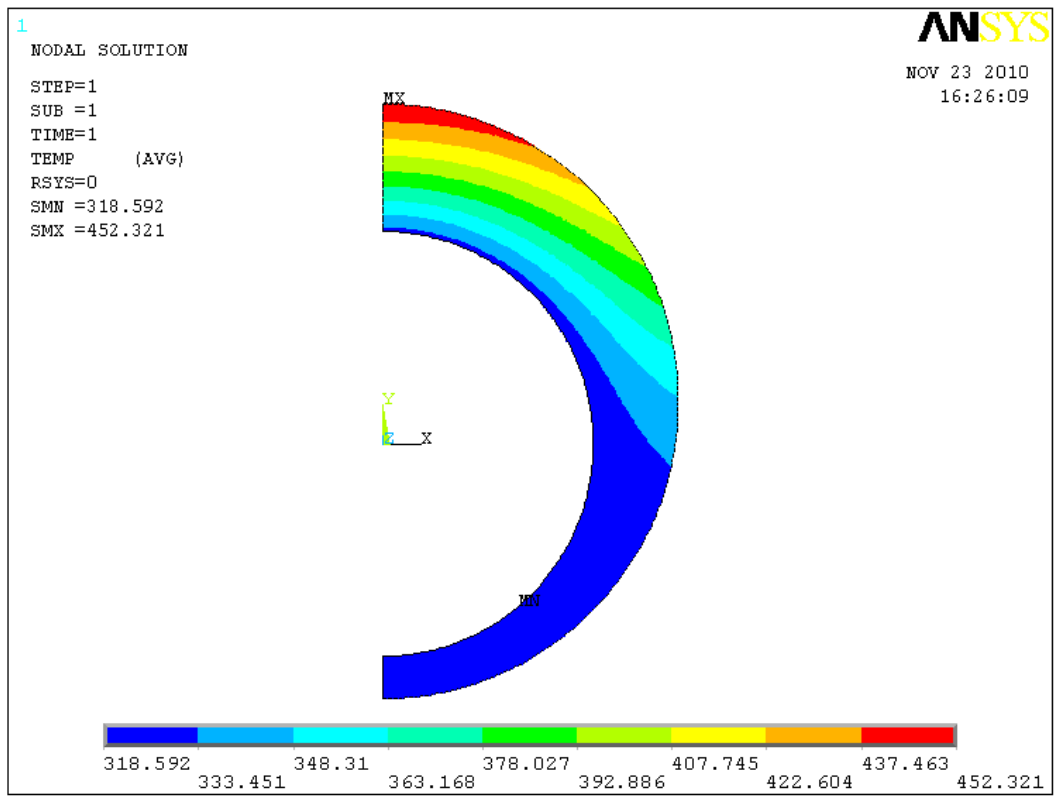

Figure 14. Computed temperature distribution in ${ }^{\circ} \mathrm{C}$ in the cross section of the heat flux tube; $q_{m}=$ $200000 \mathrm{~W} / \mathrm{m}^{2}, h=30000 \mathrm{~W} /\left(\mathrm{m}^{2} \cdot \mathrm{K}\right), T_{f}=318^{\circ} \mathrm{C}$

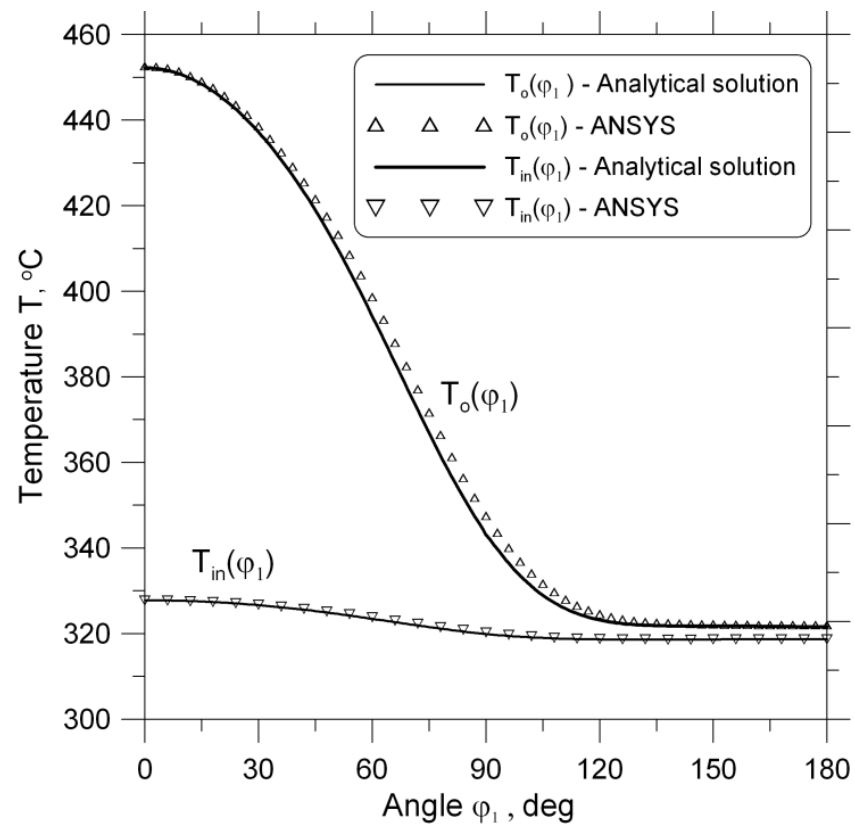

Figure 15. Temperature distribution at the inner and outer surfaces of the flux tube calculated by the analytical and finite element method 
The following input data is generated using Eq. (50): $f_{1}=437.98{ }^{\circ} \mathrm{C}, f_{2}=434.47^{\circ} \mathrm{C}$, $f_{3}=383.35{ }^{\circ} \mathrm{C}, f_{4}=380.70{ }^{\circ} \mathrm{C}, f_{5}=321.58^{\circ} \mathrm{C}$.

The following values were obtained using the proposed method: $q_{m}^{*}=200000.35 \mathrm{~W} / \mathrm{m}^{2}, h^{*}=30001.56 \mathrm{~W} /\left(\mathrm{m}^{2} \cdot \mathrm{K}\right), T_{f}^{*}=318.00{ }^{\circ} \mathrm{C}$.

In order to show the influence of the measurement errors on the determined thermal boundary parameters, the $95 \%$ confidence intervals were calculated. The following uncertainties of the measured values were assumed (at a 95\% confidence interval):

$$
2 \sigma_{f_{j}}= \pm 0.2 \mathrm{~K}, j=1, \ldots, 5,2 \sigma_{k}= \pm 0.5 \mathrm{~W} /(\mathrm{m} \cdot \mathrm{K}), 2 \sigma_{r_{j}}= \pm 0.05 \mathrm{~mm}, 2 \sigma_{\varphi_{j}}= \pm 0.5^{\mathrm{o}}, j=1, \ldots, 5 .
$$

The uncertainties (95\% confidence interval) of the coefficients $x_{i}$ were determined using the error propagation rule formulated by Gauss.

The calculation using Eq. (61) yielded the following results: $x_{1}=200000.35 \pm 3827.72 \mathrm{~W} / \mathrm{m}^{2}$, $x_{2}=30001.56 \pm 2698.81 \mathrm{~W} /\left(\mathrm{m}^{2} \cdot \mathrm{K}\right), x_{3}=318.0 \pm 0.11{ }^{\circ} \mathrm{C}$. The accuracy of the obtained results is very satisfactory. There is only a small difference between the estimated parameters and the input values. The highest temperature occurs at the crown of the flux-tube (Figures 14 and 15). The temperature of the inner surface of the flux tube is only a few degrees above the saturation temperature of the water-steam mixture. Since the heat flux at the rear side of the tube is small, the circumferential heat flow rate is significant. However, the rear surface thermocouple indicates temperatures of $2-4{ }^{\circ} \mathrm{C}$ above the saturation temperature. Therefore, the fifth thermocouple can be attached to the unheated side of the tube so as to measure the temperature of the water-steam mixture flowing through the flux tube.

In the second example, experimental results will be presented. Measurements were conducted at a 50MW pulverized coal fired boiler. The temperatures indicated by the flux tube at the elevation of $19.2 \mathrm{~m}$ are shown in Figure 16. The heat flux tube is of 20G low carbon steel with temperature dependent thermal conductivity

$$
k(T)=53.26-0.02376224 T,
$$

where the temperature $T$ is expressed in ${ }^{\circ} \mathrm{C}$ and thermal conductivity in $\mathrm{W} /(\mathrm{m} \cdot \mathrm{K})$.

The unknown parameters were determined for eight time points which are marked in Figure 16.

The inverse analysis was performed assuming the constant thermal conductivity $k(\bar{T})$ which was obtained from Eq.(64) for the average temperature: $\bar{T}=\left(T_{1}+T_{2}+T_{3}+T_{4}\right) / 4$.

The estimated parameters: heat flux $q_{m}$, heat transfer coefficient $h$, and the water-steam mixture $T_{f}$ are depicted in Figure 17. The developed flux tube can work for a long time in the destructive high temperature atmosphere of a coal-fired boiler. 


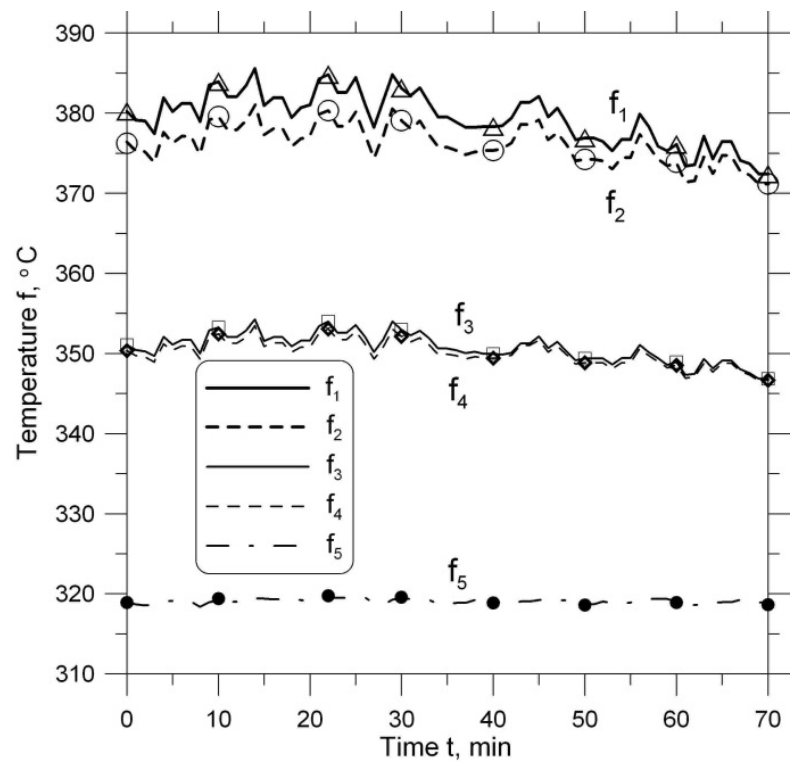

Figure 16. Measured flux tube temperatures; marks denote measured temperatures taken for the inverse analysis

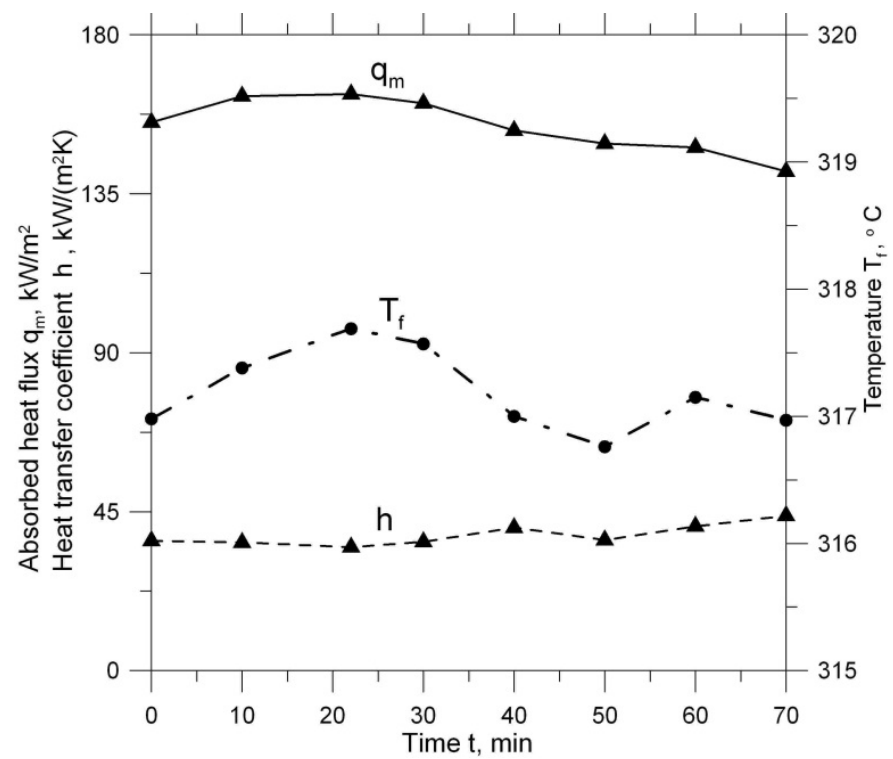

Figure 17. Estimated parameters: absorbed heat flux $q_{m}$, heat transfer coefficient $h$, and temperature of water-steam mixture $T_{f}$

Flux tubes can also be used as a local slag monitor to detect a build up of slag. The presence of the scale on the inner surface of the tube wall can also be detected. 


\section{Tubular type heat flux meter made of a finned tube}

In this section, a numerical method for determining the heat flux in boiler furnaces, based on experimentally acquired interior flux-tube temperatures, is presented. The tubular type instrument has been designed (Figure 18) to provide a very accurate measurement of absorbed heat flux $q_{m}$, inside heat transfer coefficient $h_{i n}$, and water steam temperature $T_{f}$. The number of thermocouples is greater than three because the additional information can help enhance the accuracy of parameter determining. In contrast to the existing devices, in the developed flux-tube fins are not welded to adjacent water-wall tubes. Temperature distribution in the flux-tube is symmetric and not disturbed by different temperature fields in neighboring tubes. The temperature dependent thermal conductivity of the flux-tube material was assumed. The meter is constructed from a short length of eccentric tube containing four thermocouples on the fire side below the inner and outer surfaces of the tube. The fifth thermocouple is located at the rear of the tube (on the casing side of the water-wall tube). The boundary conditions on the outer and inner surfaces of the water fluxtube must then be determined from temperature measurements in the interior locations. Four K-type sheathed thermocouples, $1 \mathrm{~mm}$ in diameter, are inserted into holes, which are parallel to the tube axis. The thermal conduction effect at the hot junction is minimized because the thermocouples pass through isothermal holes. The thermocouples are brought to the rear of the tube in the slot machined in the tube wall. An austenitic cover plate with the thickness of $3 \mathrm{~mm}$ - welded to the tube - is used to protect the thermocouples from the incident flame radiation. A K-type sheathed thermocouple with a pad is used to measure the temperature at the rear of the flux-tube. This temperature is almost the same as the watersteam temperature. An inverse problem of heat conduction was solved using the least squares method. Three unknown parameters were estimated using the LevenbergMarquardt method [23, 25]. At every iteration step, the temperature distribution over the cross-section of the heat flux meter was computed using the ANSYS CFX software

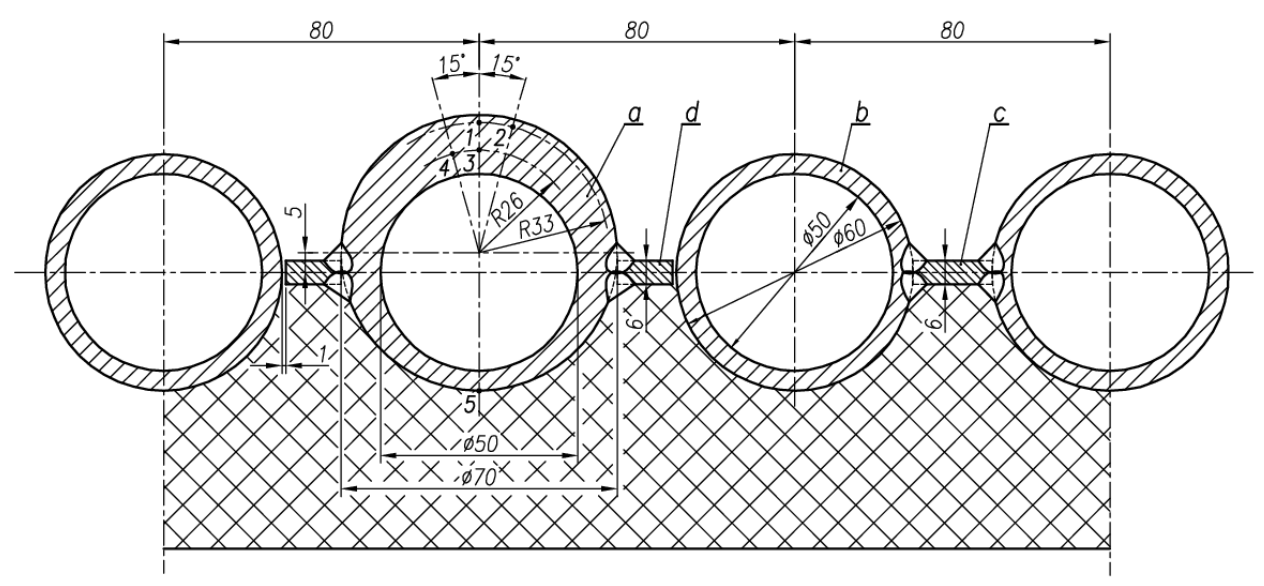

Figure 18. The cross-section of the membrane wall in the combustion chamber of the steam boiler 
Test calculations were carried out to assess accuracy of the presented method. The uncertainty in determined parameters was calculated using the Gauss variance propagation rule. The presented method is appropriate for membrane water walls (Figure 18). The new method has advantages in terms of simplicity and flexibility.

\subsection{Theory}

The furnace wall tubes in most modern units are welded together with steel bars (fins) to provide membrane wall panels which are insulated on one side and exposed to a furnace on the other, as shown schematically in Figure 18.

In a heat conduction model of the flux-tube the following assumptions are made:

- temperature distribution is two-dimensional and steady-state,

- the thermal conductivity of the flux-tube and membrane wall,

- may be dependent of temperature,

- the heat transfer coefficient $h_{\text {in }}$ and the scale thickness ds is uniform over the inner tube surface.

The temperature distribution is governed by the non-linear partial differential equation

$$
\nabla \cdot[k(T) \nabla T]=0
$$

where $\nabla$ is the vector operator, which is called nabla (gradient operator), and in Cartesian coordinates is defined by $\nabla=\mathbf{i} \partial / \partial x+\mathbf{j} \partial / \partial y+\mathbf{k} \partial / \partial z+$. The unknown boundary conditions may be expressed as

$$
\left.\left[k(T) \frac{\partial T}{\partial n}\right]\right|_{s}=q(s),
$$

where $q(s)$ is the radiation heat flux absorbed by the exposed flux tube and membrane wall surface. The local heat flux $q(s)$ is a function of the view factor $\psi(s)$ (Figure 19)

$$
q(s)=q_{m} \psi(s)
$$

where $q_{m}$ is measured heat flux (thermal loading of heating surface). The view factor $\psi(s)$ from the infinite flame plane to the differential element on the membrane wall surface can be determined graphically [7], or numerically [22].

In this chapter, $\psi(s)$ was evaluated numerically using the finite element program ANSYS [22], and is displayed in Figure 19 as a function of the extended coordinate $s$. Because of the symmetry, only the representative water-wall section illustrated in Figure 20 needs to be analyzed. The convective heat transfer from the inside tube surfaces to the water-steam mixture is described by Newton's law of cooling 


$$
-\left.\left[k(T) \frac{\partial T}{\partial n}\right]\right|_{s_{\text {in }}}=h_{\text {in }}\left(\left.T\right|_{s_{\text {in }}}-T_{f}\right),
$$

where $\partial T / \partial n$ is the derivative in the normal direction, $h_{i n}$ is the heat transfer coefficient and $T_{f}$ denotes the temperature of the water-steam mixture.

The reverse side of the membrane water-wall is thermally insulated. In addition to the unknown boundary conditions, the internal temperature measurements $f_{i}$ are included in the analysis

$$
T_{e}\left(\mathbf{r}_{i}\right)=f_{i}, \quad i=1, \ldots, m,
$$

where $m=5$ denotes the number of thermocouples (Figure 18). The unknown parameters: $x_{1}$ $=q_{m}, x_{2}=h_{i n}$, and $x_{3}=T_{f}$ were determined using the least-squares method. The symbol $r_{i n}$ denotes the inside tube radius, and $k(T)$ is the temperature dependent thermal conductivity. The object is to choose $\mathbf{x}=\left(x_{1}, \ldots, x_{n}\right)^{\mathrm{T}}$ for $n=3$ such that computed temperatures $T\left(\mathbf{x}, \mathbf{r}_{\mathbf{i}}\right)$ agree within certain limits with the experimentally measured temperatures $f_{i}$.

This may be expressed as

$$
T\left(\mathbf{x}, \mathbf{r}_{i}\right)-f_{i} \cong 0, \quad i=1, \ldots, m, \quad m=5
$$

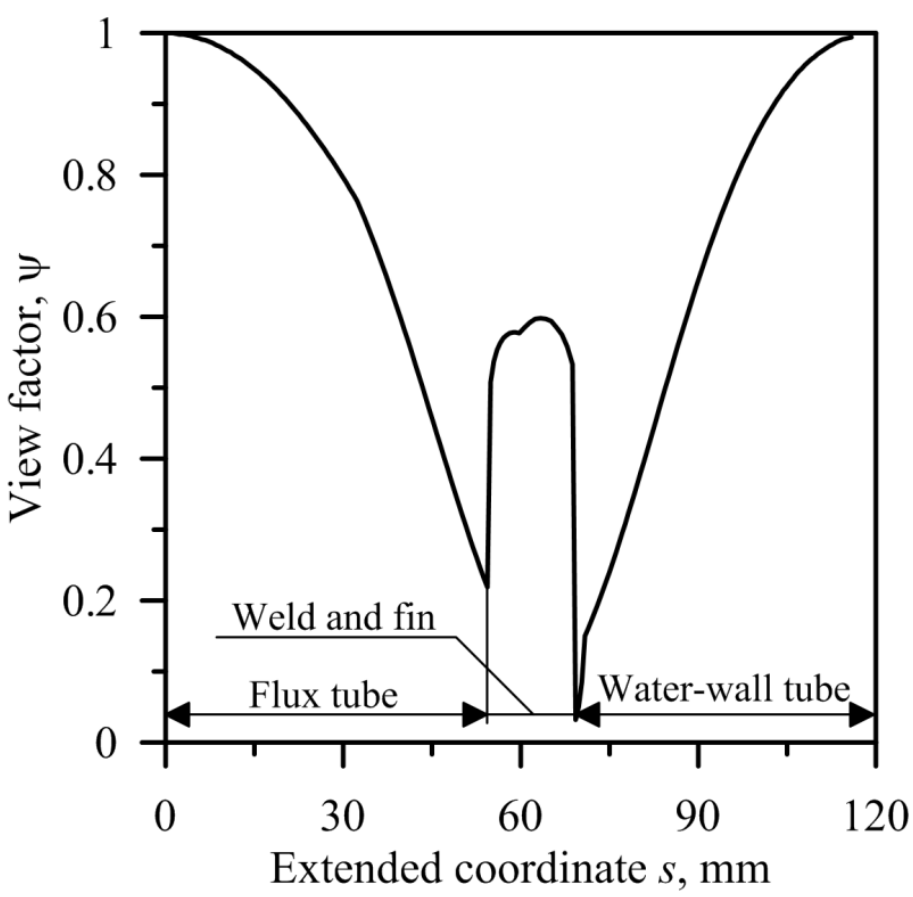

Figure 19. View factor distribution on the outer surface of water-wall tube 


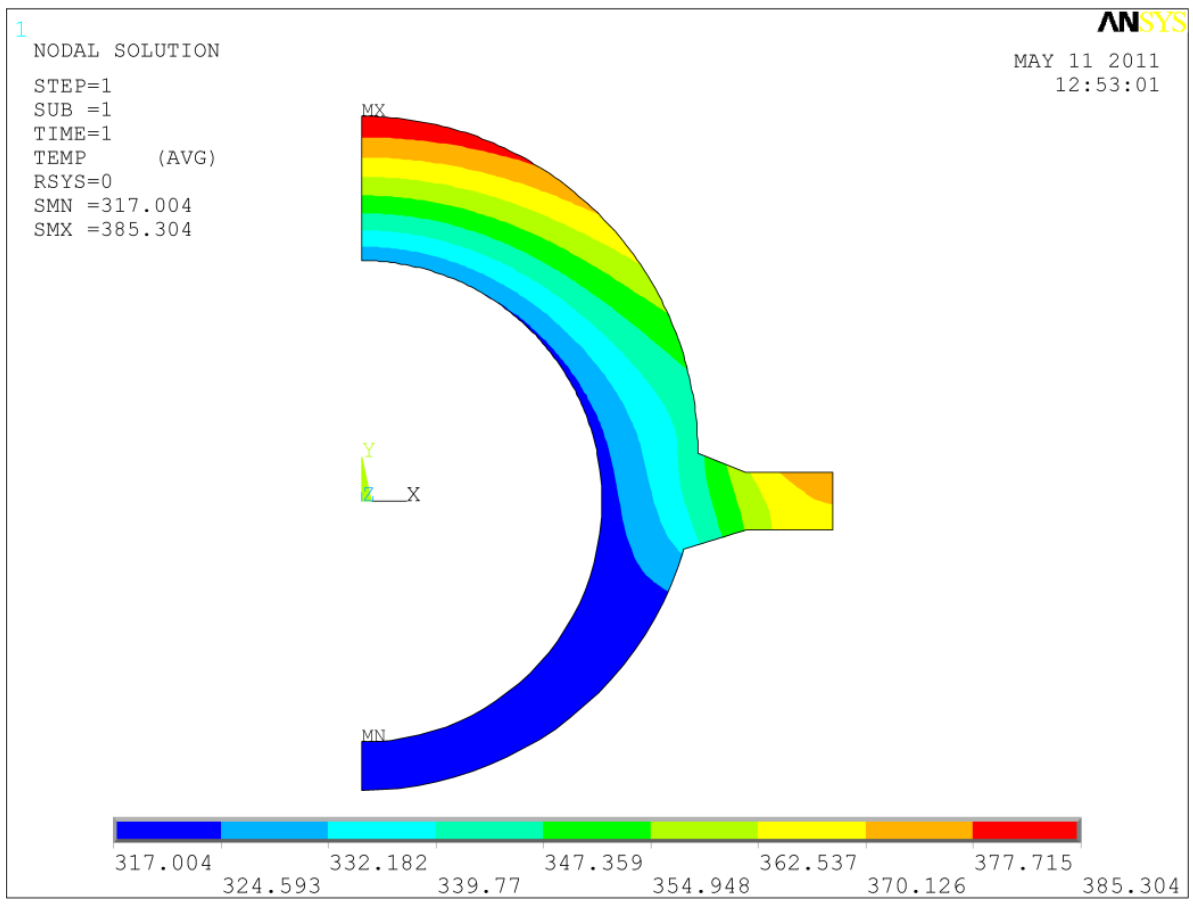

Figure 20. Temperature distribution in the flux tube cross-section for: $q_{m}=150000 \mathrm{~W} / \mathrm{m}^{2}$, $h_{\text {in }}=27000 \mathrm{~W} /\left(\mathrm{m}^{2} \cdot \mathrm{K}\right)$ and $T_{f}=317^{\circ} \mathrm{C}$

The least-squares method is used to determine parameters $\mathbf{x}$. The sum of squares

$$
S=\sum_{i=1}^{m}\left[f_{i}-T\left(\mathbf{x}, \mathbf{r}_{i}\right)\right]^{2}, \quad m=5,
$$

is minimized using the Levenberg-Marquardt method [23, 25].

The uncertainties of the determined parameters $\mathbf{x}^{*}$ will be estimated using the error propagation rule of Gauss [23-26].

\subsection{Test computations}

The flux-tubes were manufactured in the laboratory and then securely welded to the waterwall tubes at different elevations in the furnace of the steam boiler. The coal fired boiler produces $58.3 \mathrm{~kg} / \mathrm{s}$ superheated steam at $11 \mathrm{MPa}$ and $540^{\circ} \mathrm{C}$.

The material of the heat flux-tube is 20G steel. The composition of the 20G mild steel is as follows: $0.17-0.24 \% \mathrm{C}, 0.7-1.0 \% \mathrm{Mn}, 0.15-0.40 \% \mathrm{Si}, \mathrm{Max} 0.04 \% \mathrm{P}, \mathrm{Max} 0.04 \% \mathrm{~S}$, and the remainder is iron Fe. The heat flux-tube thermal conductivity is assumed to be temperature dependent (Table 1). 


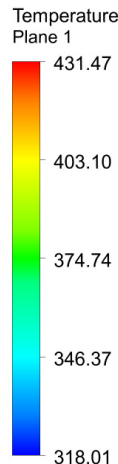

[C]

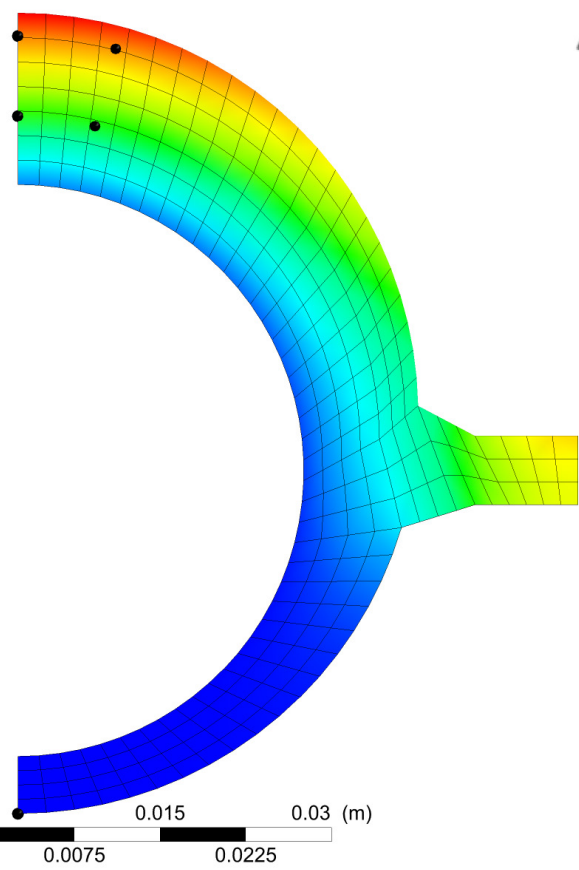

ANSYS

(a)

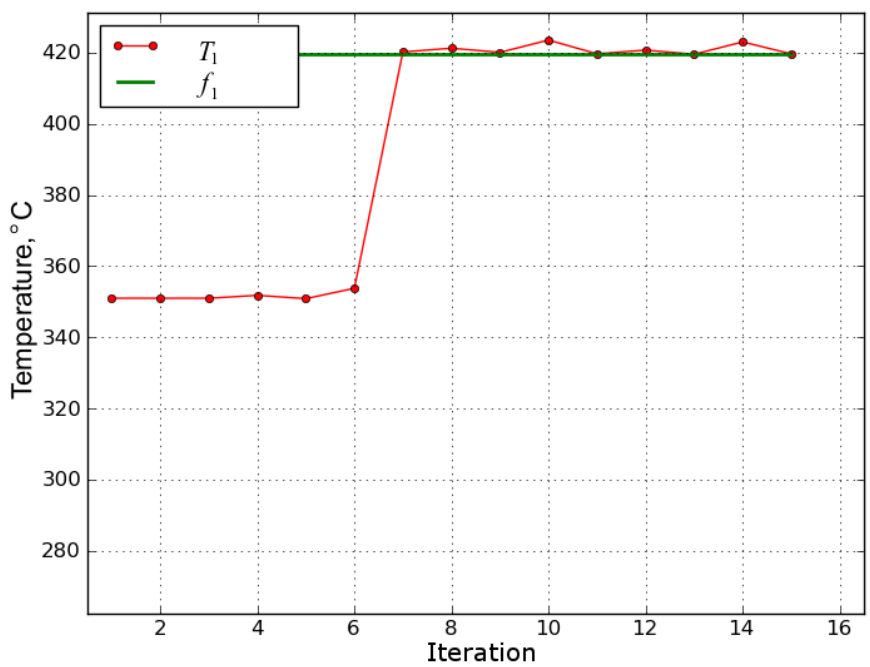

(b)

Figure 21. Solution of the inverse problem for the "exact" data: $f_{1}=419.66^{\circ} \mathrm{C}, f_{2}=417.31^{\circ} \mathrm{C}, f_{3}=374.90^{\circ} \mathrm{C}$, $f_{4}=373.19^{\circ} \mathrm{C}, f_{5}=318.01^{\circ} \mathrm{C}$; (a) - temperature distribution in the flux-tube, (b) - iteration number for the temperature $T_{1}$ 


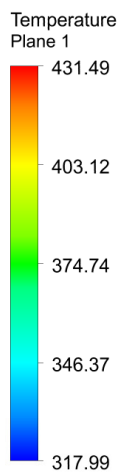

[C]

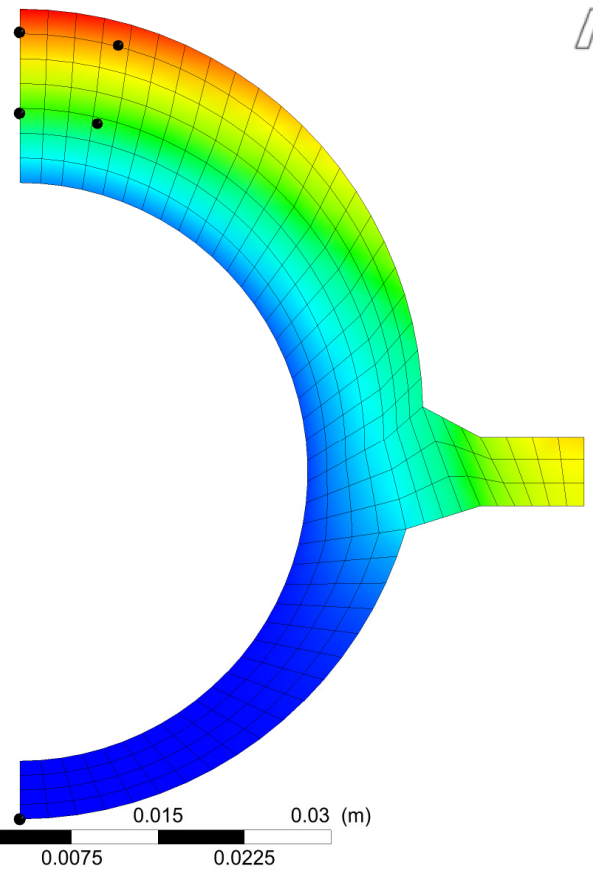

ANSYS

(a)

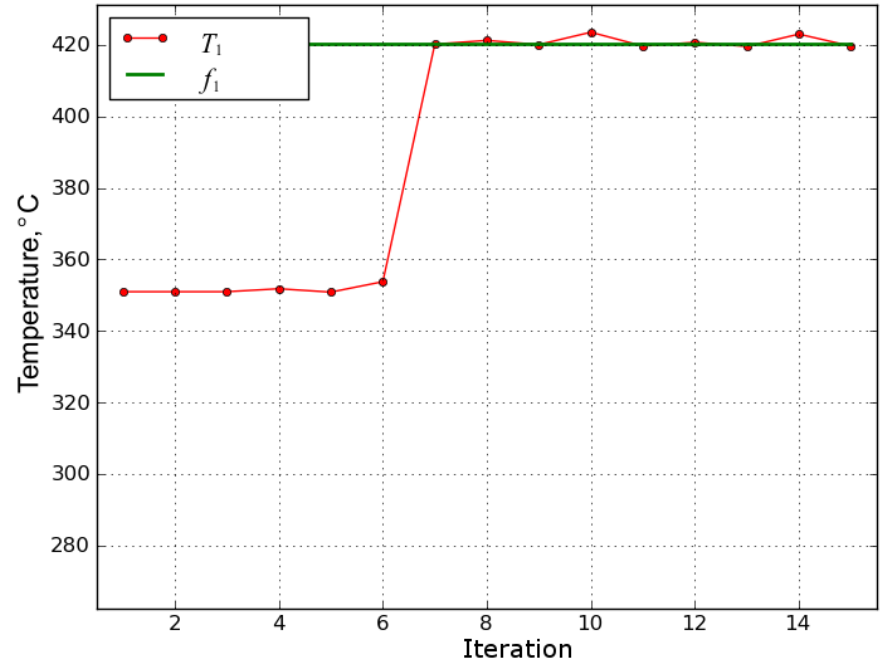

(b)

Figure 22. Solution of the inverse problem for the "perturbed" data: $f_{1}=420.16^{\circ} \mathrm{C}, f_{2}=416.81^{\circ} \mathrm{C}, f_{3}=$ $375.40^{\circ} \mathrm{C}, f_{4}=372.69^{\circ} \mathrm{C}, f_{5}=318.01^{\circ} \mathrm{C}$; (a) - temperature distribution in the flux-tube , (b) - iteration number for the temperature $T_{1}$ 


\begin{tabular}{|l|c|c|c|c|}
\hline Temperature $T,{ }^{\circ} \mathrm{C}$ & 100 & 200 & 300 & 400 \\
\hline Thermal conductivity $k, \mathrm{~W} /(\mathrm{m} \cdot \mathrm{K})$ & 50.69 & 48.60 & 46.09 & 42.30 \\
\hline
\end{tabular}

Table 1. Thermal conductivity $k(T)$ of steel $20 \mathrm{G}$ as a function of temperature

To demonstrate that the maximum temperature of the fin tip is lower than the allowable temperature for the $20 \mathrm{G}$ steel, the flux tube temperature was computed using ANSYS CFX package [22]. Changes of the view factor on the flux tube, weld and fin surface were calculated with ANSYS CFX. The temperature distribution shown in Figure 20 was obtained for the following data: absorbed heat flux, $q_{m}=150000 \mathrm{~W} / \mathrm{m}^{2}$, temperature of the watersteam mixture, $T_{f}=317^{\circ} \mathrm{C}$, and heat transfer coefficient at the tube inner surface, $h_{i n}=27000$ $\mathrm{W} /\left(\mathrm{m}^{2} \cdot \mathrm{K}\right)$. An inspection of the results shown in Figure 20 indicates that the maximum temperature of the fin does not exceed $375^{\circ} \mathrm{C}$.

Next, to illustrate the effectiveness of the presented method, test calculations were carried out. The "measured" temperatures $f_{i}, i=1,2, \ldots, 5$ were generated artificially by means of ANSYS CFX for: $q_{m}=250000 \mathrm{~W} / \mathrm{m}^{2}$, $h_{i n}=30000 \mathrm{~W} /\left(\mathrm{m}^{2} \cdot \mathrm{K}\right)$ and $T_{f}=318^{\circ} \mathrm{C}$. The following values of "measured" temperatures were obtained $f_{1}=419.66^{\circ} \mathrm{C}, f_{2}=417.31^{\circ} \mathrm{C}, f_{3}=374.90^{\circ} \mathrm{C}$, $f_{4}=373.19^{\circ} \mathrm{C}, f_{5}=318.01^{\circ} \mathrm{C}$. The temperature distribution in the flux tube cross-section, reconstructed on the basis of five measured temperatures is depicted in Figure 21a.

The proposed inverse method is very accurate since the estimated parameters: $q_{m}=$ $250000.063 \mathrm{~W} / \mathrm{m}^{2}, h_{i n}=30000.054 \mathrm{~W} /\left(\mathrm{m}^{2} \cdot \mathrm{K}\right)$ and $T_{f}=318.0^{\circ} \mathrm{C}$ differ insignificantly from the input values. In order to show the influence of the measurement errors on the determined parameters, the $95 \%$ confidence intervals were estimated. The following uncertainties of the measured values were assumed (at 95\% confidence interval): $2 \sigma_{f_{j}}= \pm 0.5 \mathrm{~K}, j=1,2, \ldots, 5$, $2 \sigma_{k}= \pm 1 \mathrm{~W} /(\mathrm{m} \cdot \mathrm{K}), 2 \sigma_{r_{j}}= \pm 0.05 \mathrm{~mm}, 2 \sigma_{\varphi_{j}}= \pm 0.5^{\circ}, \quad j=1, \ldots, 5$. The uncertainties (95\% confidence interval) of the coefficients $x_{i}$ were determined using the error propagation rule formulated by Gauss [23-26]. The calculated uncertainties are: $\pm 6 \%$ for $q_{m}, \pm 33 \%$ for $h_{\text {in }}$ and $\pm 0.3 \%$ for $T_{f}$. The accuracy of the results obtained is acceptable.

Then, the inverse analysis was carried out for perturbed data: $f_{1}=420.16^{\circ} \mathrm{C}, f_{2}=416.81^{\circ} \mathrm{C}, f_{3}=$ $375.40^{\circ} \mathrm{C}, f_{4}=372.69^{\circ} \mathrm{C}, f_{5}=318.01^{\circ} \mathrm{C}$. The reconstructed temperature distribution illustrates Figure 22a.

The obtained results are: $q_{m}=250118.613 \mathrm{~W} / \mathrm{m}^{2}, h_{i n}=30050.041 \mathrm{~W} /\left(\mathrm{m}^{2} \cdot \mathrm{K}\right)$ and $T_{f}=317.99^{\circ} \mathrm{C}$. The errors in the measured temperatures have little effect on the estimated parameters. The number of iterations in the Levenberg-Marquardt procedure is small in both cases (Figures $21 b$ and $22 b)$.

\section{Conclusions}

Two different tubular type instruments (flux tubes) were developed to identify boundary conditions in water wall tubes of steam boilers. The first measuring device is an eccentric tube. The ends of the four thermocouples are located at the fireside part of the tube and the 
fifth thermocouple is attached to the unheated rear surface of the tube. The meter presented in the paper has one particular advantage over the existing flux tubes to date. The temperature distribution in the flux tube is not affected by the water wall tubes, since the flux tube is not connected to adjacent waterwall tubes with metal bars, referred to as membrane or webs. To determine the unknown parameters only the temperature distribution at the cross section of the flux tube must be analyzed.

The second flux tube has two longitudinal fins. Fins attached to the flux tube are not welded to the adjacent water-wall tubes, so the temperature distribution in the measuring device is not affected by neighboring water-wall tubes. The installation of the flux tube is easier because welding of fins to adjacent water-wall tubes is avoided. Based on the measured flux tube temperatures the non-linear inverse heat conduction problem was solved. A CFD based method for determining heat flux absorbed water wall tubes, heat transfer coefficient at the inner flux tube surface and temperature of the water-steam mixture has been presented. The proposed flux tube and the inverse procedure for determining absorbed heat flux can be used both when the inner surface of the heat flux tube is clean and when scale or corrosion deposits are present on the inner surface what can occur after a long time service of the heat flux tube.

The flux tubes can work for a long time in the destructive high temperature atmosphere of a coal-fired boiler.

\section{Nomenclature}

a inner radius of boiler tube and flux-tube $(\mathrm{m})$

$b \quad$ outer radius of flux-tube $(\mathrm{m})$

$\mathrm{Bi} \quad$ Biot number, $B i=h a / k$

$c \quad$ outer radius of boiler tube $(\mathrm{m})$

e eccentric $(\mathrm{m})$

$f_{\mathrm{i}} \quad$ measured wall temperature at the $i$-th location $\left({ }^{\circ} \mathrm{C}\right.$ or $\left.\mathrm{K}\right)$

f vector of measured wall temperatures

$h \quad$ heat transfer coefficient $\left(\mathrm{W} /\left(\mathrm{m}^{2} \cdot \mathrm{K}\right)\right)$

In identity matrix

J Jacobian matrix of $\mathbf{T}$

$k \quad$ thermal conductivity $(\mathrm{W} /(\mathrm{m} \cdot \mathrm{K}))$

$l \quad$ arbitrary length of boiler tube $(\mathrm{m})$

$m \quad$ number of temperature measurement points

$n \quad$ number of unknown parameters

$q_{m} \quad$ heat flux to be determined (absorbed heat flux referred to the projected furnace water wall surface) $\left(\mathrm{W} / \mathrm{m}^{2}\right)$

$r \quad$ coordinate in cylindrical coordinate system or radius (m)

$r_{\mathrm{i}} \quad$ radial coordinate of the $i$-th thermocouple $(\mathrm{m})$

$r_{i n} \quad$ inner radius of the flux-tube $(\mathrm{m})$

$r_{0} \quad$ outer radius of the flux-tube $(\mathrm{m})$ 


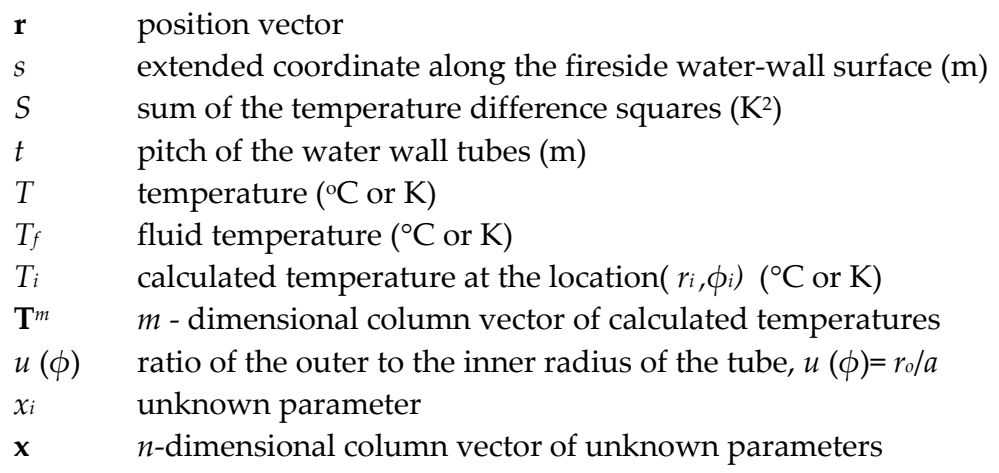

\section{Greek symbols}

$\alpha, \beta, \gamma, \delta_{1}, \delta_{2}, \varepsilon$
$\theta$
$\phi$
$\phi_{i}$
$\mu$
$\psi$

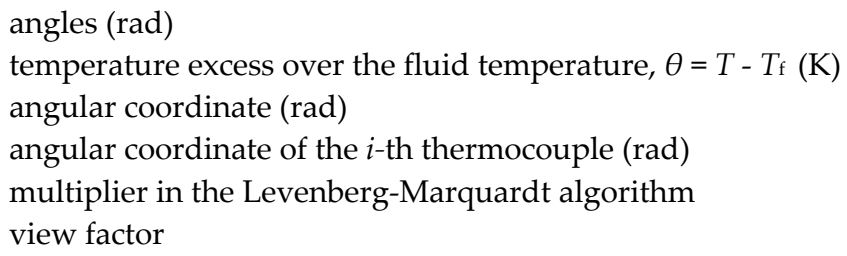

\section{Subscripts}

$\begin{array}{ll}\text { in } & \text { inner } \\ o & \text { outer } \\ i & i \text {-th temperature measurement point } \\ f & \text { fluid }\end{array}$

\section{Author details}

Jan Taler

Department of Thermal Power Engineering, Cracow University of Technology, Cracow, Poland

Dawid Taler

Institute of Heat Transfer Engineering and Air Protection, Cracow University of Technology,

Cracow, Poland

\section{References}

[1] Segeer M, Taler J (1983) Konstruktion und Einsatz transportabler Wärmeflußsonden zur Bestimmung der Heizflächenbelastung in Feuerräumen. Fortschr.-Ber. VDI Zeitschrift, Reihe 6, Nr 129. Düsseldorf : VDI-Verlag.

[2] Northover EW, Hitchcock JA (1967) A Heat Flux Meter for Use in Boiler Furnaces. J. Sci. Instrum. 44: 371-374. 
[3] Neal SBH, Northover EW (1980) The Measurement of Radiant Heat Flux in Large Boiler Furnaces-I. Problems of Ash Deposition Relating to Heat Flux. Int. J. Heat Mass Transfer 23: 1015-1022.

[4] Arai N, Matsunami A, Churchill S (1996) A Review of Measurements of Heat Flux Density Applicable to the Field of Combustion. Exp. Therm. Fluid Sci. 12: 452-460.

[5] Taler J (1990) Measurement of Heat Flux to Steam Boiler Membrane Water Walls. VGB Kraftwerkstechnik 70: 540-546.

[6] Taler J (1992) A Method of Determining Local Heat Flux in Boiler Furnaces. Int. J. Heat Mass Transfer 35:1625-1634.

[7] Taler J (1990) Messung der lokalen Heizflächenbelastung in Feuerräumen von Dampferzeugern. Brennstoff-Wärme-Kraft (BWK) 42: 269-277.

[8] Fang Z, Xie D, Diao N, Grace JR, Lim CJ (1997) A New Method for Solving the Inverse Conduction Problem in Steady Heat Flux Measurement. Int. J. Heat Mass Transfer 40: 3947-3953.

[9] Luan W, Bowen BD, Lim CJ, Brereton CMH, Grace JR (2000) Suspension-to MembraneWall Heat Transfer in a Circulating Fluidized Bed Combustor. Int. J. Heat Mass Transfer 43: 1173-1185.

[10] Taler J, Taler D (2007) Tubular Type Heat Flux Meter for Monitoring Internal Scale Deposits in Large Steam Boilers. Heat Transfer Engineering 28: 230-239.

[11] Sobota T, Taler D (2010) A Simple Method for Measuring Heat Flux in Boiler Furnaces. Rynek Energii 86: 108-114.

[12] Taler D, Taler J, Sury A (2011) Identification of Thermal Operation Conditions of Water Wall Tubes Using Eccentric Tubular Type Meters. Rynek Energii 92: 164-171.

[13] Taler J, Taler D, Kowal A (2011) Measurements of Absorbed Heat Flux and Water-side Heat Transfer Coefficient in Water Wall Tubes. Archives of Thermodynamics 32: 77 88.

[14] Taler J, Taler D, Sobota T, Dzierwa P (2011) New Technique of the Local Heat Flux Measurement in Combustion Chambers of Steam Boilers. Archives of Thermodynamics 32: 103-116.

[15] LeVert FE, Robinson JC, Frank RL, Moss RD, Nobles WC, Anderson AA (1987) A Slag Deposition Monitor for Use in Coal_Fired Boilers. ISA Transactions 26: 51-64

[16] LeVert FE, Robinson JC, Barrett SA, Frank RL, Moss RD, Nobles WC, Anderson AA (1988) Slag Deposition Monitor for Boiler Performance Enhancement. ISA Transactions 27: 51-57

[17] Vallero A, Cortes C (1996) Ash Fouling in Coal-Fired Utility Boilers. Monitoring and Optimization of On-Load Cleaning. Prog. Energy. Combust. Sci. 22: 189-200.

[18] Teruel E, Cortes C, Diez LI, Arauzo I (2005) Monitoring and Prediction of Fouling in Coal-Fired Utility Boilers Using Neural Networks. Chem. Eng. Sci. 60: 5035-5048.

[19] Taler J, Trojan M, Taler D (2011) Monitoring of Ash Fouling and Internal Scale Deposits in Pulverized Coal Fired Boilers. New York: Nova Science Publishers.

[20] Howell JR, Siegel R, Mengüç MP (2011) Thermal Radiation Heat Transfer. Boca Raton: CRC Press - Taylor \& Francis Group.

[21] Sparrow FM, Cess RD (1978) Radiation Heat Transfer. New York: McGraw-Hill. 
[22] ANSYS CFX 12. (2010) Urbana, Illinois, USA: ANSYS Inc.

[23] Seber GAF, Wild CJ (1989) Nonlinear regression. New York: Wiley.

[24] Policy on reporting uncertainties in experimental measurements and results (2000). ASME J. Heat Transfer 122: 411-413.

[25] Press WH, Teukolsky SA, Vetterling WT, Flannery BP (2006) Numerical Recipes in Fortran. The Art of Scientific Computing. Cambridge: Cambridge University Press.

[26] Coleman HW, Steele WG (2009) Experimentation, Validation, and Uncertainty Analysis for Engineers. Hoboken: Wiley. 